\title{
1 Genetic architecture of oxidative stress tolerance in the fungal wheat pathogen
}

2

3

4

5

6 Plant Pathology Group, Institute of Integrative Biology, ETH Zurich, 8092 Zürich,

7 Switzerland

8

* New address: Department of Biointeractions and Crop Protection, Rothamsted Research,

9 Harpenden, UK 
12 RUNNING TITLE: Genetic architecture of oxidative stress tolerance in $Z$. tritici

14 KEYWORDS: Quantitative trait locus mapping; oxidative stress; plant pathogen; fungi;

15 Zymoseptoria tritici

16

17 CORREPONDING AUTHORS:

18 Bruce A. McDonald,

19 Department of Environmental Systems Science,

20 ETH Zurich,

21 LFW B16,

22 Universitätstrasse 2,

238092 Zurich,

24 Switzerland.

25 Phone number: +41446323847

26 Email: bruce.mcdonald@usys.ethz.ch

27

28 Javier Palma Guerrero,

29 Biointeractions and Crop Protection,

30 Rothamsted Research,

31 AL5 2JQ Harpenden,

32 United Kingdom

33 Phone number: +44(0) 1582938591

34 Email: Javier.palma-guerrero@rothamsted.ac.uk 


\section{ABSTRACT}

36 Reactive oxygen species are toxic byproducts of aerobic respiration produced during cell

37 growth. They also are an important component of plant defenses to inhibit microbial pathogens.

38 Tolerance to oxidative stress contributes to viability and pathogenicity of plant pathogens.

39 However, the complex molecular network of oxidative stress responses hinders identification

40 of the genes contributing to variation in this trait. Variation in genes affecting responses to oxidative stress is likely to affect the evolutionary potential of pathogen tolerance to host defences. Here, we employed a forward genetic approach to investigate the genetic architecture of oxidative stress tolerance in the fungal wheat pathogen Zymoseptoria tritici. By performing

44 quantitative trait locus (QTL) mapping in two crosses, we identified several genomic regions associated with tolerance to oxidative stress, including a QTL having a large effect on growth under oxidative stress. We found evidence for a significant trade-off between growth under non-stressful conditions and growth inhibition under oxidative stress. We identified a large QTL associated with this trade-off and with growth under non-stressful conditions, suggesting that differences in fungal growth could result in different sensitivities to oxidative stress. Our results suggest that genes related to fungal growth could also contribute to variation in oxidative stress tolerance among fungal strains. 


\section{INTRODUCTION}

Reactive oxygen species (ROS) are toxic free radicals that can oxidize biomolecules and disturb basic metabolism. Aerobic microbes produce a large amount of ROS that may interfere with metabolism as a normal byproduct of respiration during cell growth (Heller \& Tudzynski 2011; Segal \& Wilson 2018). Cells can also be exposed to an endogenous ROS burst when experiencing environmental changes and abiotic stresses, such as thermal stress (Trachootham et al. 2008; Gocheva et al. 2009; Heller \& Tudzynski 2011). During plant-pathogen interactions, ROS are secreted by plants within minutes to act as secondary signals to trigger plant defenses, and then peak during the hypersensitive response to isolate pathogens locally (Doehlemann \& Hemetsberger 2013). Hence, the efficient elimination of excessive ROS and the ability to grow under oxidative stress are important traits for fungal pathogens during plant infection.

Different chemicals and enzymes can be synthesized to counteract the effects of oxidative stress (Thorpe et al. 2004; Heller \& Tudzynski 2011; Segal \& Wilson 2018). Enzymes such as superoxide dismutases (SOD), catalases, and catalase-peroxidases are induced in oxidative stress environments (Broxton \& Culotta 2016; Papadakis \& Workman 2014). Reductases and peroxidases employing thioredoxin and glutathione as electron donors were also reported to be important for ROS reduction (Fernandez \& Wilson 2014; Yang et al. 2016; Ma et al. 2018). The NADPH oxidase complex (NOX) involved in ROS generation was also reported to be associated with sensitivity to oxidative stress (Chen et al. 2014). Other molecules found in fungi, including melanin and carotene, were also suggested to protect cells from ROS (Jacobson 2000; Heller \& Tudzynski 2011). Oxidative stress responses were found to be largely regulated by the transcription factor Yap1 and the MAPK pathways (Molina \& Kahmann 2007; Segmüller et al. 2007; Walia \& Calderone 2008; Lin et al. 2009; Ronen et al. 
fungi, referred to as core environmental stress response (CESR) genes, such as Msn2 and Msn4, were also found to be involved in the oxidative stress response in fission yeast (Chen et al. $2003 ; 2008)$.

83

Results from previous studies suggested that other unknown genes also affect oxidative stress tolerance and that there are genes with dispensable and overlapping functions that decrease the effects of ROS (Grant et al. 1997; Rolke et al. 2004; Gohari et al. 2015; Segal \& Wilson 2018).

Transcriptomic studies in fission yeast showed that a complex network of hundreds of genes is involved in the oxidative stress response (Chen et al. 2008). This complex network was affected by the exposure time, ROS dose, ROS location and the species. In such complex gene networks, it is difficult to determine which genes contribute to the tolerance to oxidative stress and whether these genes retain a high evolutionary potential in natural populations. Most previous studies in fungal plant pathogens determined the functions of major ROS scavengers by analyzing single gene mutations (Heller \& Tudzynski 2011; Segal \& Wilson 2018). We hypothesized that association mapping would provide more powerful insights into the evolution of this complex trait by enabling a whole-genome perspective. Combining genotypic and phenotypic variation can enable identification of important genomic regions or genes that contribute to the variation in oxidative stress tolerance. Association mapping studies utilizing wild-type strains can provide insight into the evolution of this trait in natural populations.

100 The fungus Zymoseptoria tritici has been successfully used in quantitative trait locus (QTL) mapping and genome-wide association studies (GWAS) (Lendenmann et al. 2014; 2015; 2016; Hartmann et al. 2017; Stewart et al. 2018). This pathogen reduces wheat yields globally by damaging infected leaves (Torriani et al. 2015). Z. tritici is a latent necrotroph with a long asymptomatic phase that varies according to the combination of pathogen strain and host 
cultivars (Sanchez-Vallet et al. 2015). Previous studies in Z. tritici considered the importance compatible infection: a weak burst during the latent phase (around 5 days post inoculation, dpi) and a strong burst that occurred during the start of the necrotrophic phase (around 13 dpi)

109 (Shetty et al. 2003). It was found that infiltration of catalase into infected leaves increased 110 disease symptoms and accelerated disease development, while infiltration of hydrogen 111 peroxide $\left(\mathrm{H}_{2} \mathrm{O}_{2}\right)$ decreased the disease symptoms and delayed fungal sporulation (Shetty et al.

112 2007). These experiments illustrated the importance of ROS tolerance during plant infection.

114 Some genes involved in the oxidative stress response have already been characterized in $Z$.

115 tritici. A catalase-peroxidase $(Z t C p x l)$ was found to be essential for growth in vitro in the 116 presence of hydrogen peroxide and for disease development during plant infection (Gohari et al. 2015). Another catalase-peroxidase (ZtCpx2) was found to be dispensable for the in vitro oxidative stress response but it was important for the transition from the biotrophic to the

119 necrotrophic phase during plant infection (Gohari et al. 2015). The major oxidative stress regulator Yap1 was also identified in Z. tritici, and was found to be essential for in vitro tolerance to oxidative stress but not for in planta virulence (Yang et al. 2015). These results confirmed the importance of some known ROS management systems in Z. tritici and illustrated the need for further studies to identify other genes involved in oxidative stress tolerance.

In this study, we investigated the genetic architecture of oxidative stress tolerance in Z. tritici by performing quantitative trait locus (QTL) mapping of tolerance to hydrogen peroxide under axenic conditions in two segregating populations. Significant QTLs were compared in the presence or absence of oxidative stress to infer the biological functions of the QTLs. Large- 
genes related to oxidative stress tolerance by combining previously published in planta and in vitro RNAseq datasets. We identified several QTLs associated with oxidative stress tolerance, including one QTL strongly associated with growth under oxidative stress. Our data also indicated a trade-off between growth under non-stressful conditions and growth inhibition under oxidative stress, indicating that genes contributing to general growth may also affect stress tolerance. This study suggests that the natural variation in oxidative stress tolerance could reflect variation both in genes specific for oxidative stress response and genes related to fungal growth under non-stressful conditions.

\section{MATERIALS AND METHODS}

\section{Phenotyping for oxidative stress tolerance in vitro}

141 Two crosses among four Swiss strains of Z. tritici (1E4 x 1A5 and 3D1 x 3D7) generated 249 and 257 offspring, respectively, as reported in previous studies (Lendenmann et al. 2014; 2015; 2016). The four parents and their 506 progeny were separated into 20 sets to phenotype for oxidative stress tolerance as follows. Spores were recovered from glycerol stocks kept at -80 ${ }^{\circ} \mathrm{C}$ and grown in YPD (yeast potato dextrose) media for 5 days at $18^{\circ} \mathrm{C}$ on a shaker at $120 \mathrm{rpm}$.

146 The spore suspensions were filtered through a double layer of sterilized cheesecloth and then

147 centrifuged at $3273 \mathrm{~g}$ for $15 \mathrm{~min}$. The spore pellets were diluted to a concentration of 200

148 spores per ml, and $200 \mu \mathrm{l}$ of the spore solution was added to each PDA (Difco potato dextrose 149 agar) Petri plate to obtain around 40 colonies per plate. To create the oxidative stress 150 environment, $113 \mu \mathrm{l}$ of $30 \% \mathrm{H}_{2} \mathrm{O}_{2}$ (SIGMA-ALDRICH Chemio GmbH) was added into one

151 liter of autoclaved and cooled $\left(<60^{\circ} \mathrm{C}\right)$ PDA media to produce a final concentration of 1.0 $\mathrm{mM} \mathrm{H}_{2} \mathrm{O}_{2}$. Unamended PDA was used as the control environment. Each strain was inoculated onto three replicate Petri plates for each environment. All plates were incubated at $18{ }^{\circ} \mathrm{C}$ in the 
dark. Digital images of each plate were acquired at 8- and 12-days post inoculation (dpi) as described by Lendenmann et al. (2014).

157 To measure colony area $\left(\mathrm{cm}^{2}\right)$ and the degree of melanization, all images were processed in 158 MatLab R2017b (The MathWorks, Inc., Natick, Massachusetts, United States) using a purpose159 developed script (File S1) based on instructions given in the Image Segmentation Tutorial by 160 Image Analyst (https://ch.mathworks.com/matlabcentral/fileexchange/25157-image-

161 segmentation-tutorial). Colony radii were calculated as radii $=\sqrt{\text { Colony area } / \pi}$. To measure melanization of each colony, gray scale values were obtained from RGB color values by using the rgb2gray function in MatLab. Higher gray values indicate lower melanization on the $0-255$ gray scale, where 0 is completely black and 255 is completely white. The average colony radius and average gray value for each isolate under each condition was calculated for each plate, and the mean value across the three replicates was used as the phenotype input for growth and melanization in the QTL mapping. We also calculated the growth rate and melanization rate between 8 and $12 \mathrm{dpi}$, as the colony growth between these time points was found to be linear in a previous study (Lendenmann et al., 2015). As most strains showed different growth

170 patterns under stressed and non-stressed conditions, the relative values of growth or melanization, representing the percentage of growth reduction or increase in melanization due to oxidative stress, were calculated for each strain to estimate differences in sensitivity to oxidative stress among offspring. All phenotypes used as inputs for QTL mapping were calculated as shown below, and all statistical analyses were performed in R (R Core Team, 2018). 
Growth_Rate $=($ Radius $12 d p i-$ Radius8dpi $) / \Delta D p i(12-8)$

Melanization_Rate $=\left(\right.$ Gray $_{12 d p i}-$ Graysdpi $) / \Delta$ Dpi $(12-8)$

Value (relative) $=$ Value (in oxidative stress environment)/Value (in control environment)

To estimate the phenotypic variation resulting from the genetic variation, broad-sense

184 heritability was calculated as $\sigma_{G}^{2} /\left(\sigma_{G}^{2}+\sigma_{E}^{2}\right)$ (Bloom et al. 2013), where $\sigma_{G}^{2}$ is the genetic variance and $\sigma_{E}^{2}$ is the residual variance. The calculation of these two variance components was performed using mixed models with strain, replicate and set as random effects in the sommer package (Covarrubias-Pazaran 2016) in R. To detect transgressive segregation, we performed Dunnett's test to identify any segregants with mean values either significantly higher or lower than the parents $(\mathrm{p}<0.001)$ (Johansen-Morris et al. 2006). The Dunnett's tests were performed by using replicates in the multcomp package (Hothorn et al. 2008) in R.

\section{Genotype data and QTL mapping}

SNP data used for QTL mapping were obtained from RADseq data generated previously

194 (Lendenmann et al. 2014), but using the finished genome sequence of one of the parental strains

195 (Plissonneau et al. 2018) as the reference genome for each cross (1A5 for the 1E4 x 1 A5 cross and 3D7 for the 3D1 x 3D7 cross). The SNP markers were generated and filtered as described in previous studies (Zhong et al. 2017; Meile et al. 2018). This provided 35030 SNP markers in the $1 \mathrm{E} 4 \times 1 \mathrm{~A} 5$ cross and 57513 SNP markers in the 3D1 x 3D7 cross, leading to average marker distances of 0.31 and $0.10 \mathrm{cM}(1145$ and $658 \mathrm{bp})$ respectively. Single-QTL genome scans using standard interval mapping were performed to provide an overview of the genetic architecture of each trait. All QTL analyses were performed using the $R / q t l$ package (Broman et al. 2003) in R, following the instructions in 'A Guide to QTL Mapping with R/qtl' (Broman 
the entire genome. Genes located within the $95 \%$ Bayes credibility intervals were identified according to the genome annotations of the reference parental strains (Plissonneau et al. 2018).

\section{Identification of candidate genes within QTL confidence intervals}

Only QTLs with high LOD scores (LOD > 10) were included in the analyses aiming to identify candidate genes associated with each trait. All candidate genes were BLASTed to the NCBI

210 database (https://blast.ncbi.nlm.nih.gov/Blast.cgi) to confirm their functional domains and to

211 search for homology to functionally characterized genes. Sequence variation among the

212 parental strains in the QTL confidence intervals was identified by performing sequence 213 alignments (CLC Sequence Viewer 7.6.1, QIAGEN Aarhus A/S). The previously published in 214 planta expression data (Palma-Guerrero et al. 2017) at 7 dpi and in vitro expression data

215 (Francisco et al. 2019) obtained for the four parental strains were used to confirm the gene models and to compare the expression of candidate genes. Genes with at least one sequence

217 variant among the parental strains in either the protein-encoding sequence or the 5'- or 3'- UTR regions were considered to be top candidates to explain the observed marker-trait associations.

\section{In planta expression of candidate genes}

221 To clarify the possible in planta function of candidate genes, we used the in planta expression data obtained in a previous study for the 3D7 parent (Palma-Guerrero et al. 2016), which consisted of five time points, covering the complete life cycle of the fungus in wheat leaves.

We analyzed the expression of the top candidate genes and compared them to genes known to encode domains involved in the oxidative stress response. For this analysis we focused only on genes with homology to genes already known to be related to oxidative stress in fungi. 


\section{RESULTS}

\section{9 \\ Variation in growth and melanization}

230 Two segregating F1 populations of $Z$. tritici were scored for growth and melanization in the

231 presence and absence of hydrogen peroxide. Growth of nearly all strains was inhibited (i.e.

232 relative growth was $<1$ ) by $1 \mathrm{mM} \mathrm{H}_{2} \mathrm{O}_{2}$ at $8 \mathrm{dpi}$ in both crosses (Figure 1A, left panel), but the

233 degree of inhibition varied among strains. The 1E4 and 1A5 parental strains showed similar

234 levels of growth inhibition $(1 \mathrm{~A} 5=0.68 \pm 0.01,1 \mathrm{E} 4=0.62 \pm 0.04)$ under oxidative stress, but a total of 94 of their offspring exhibited growth inhibition significantly $(\mathrm{p}<0.001)$ higher than 1A5 or lower than 1E4 (Figures 1A and 1B). We interpreted this as evidence of transgressive segregation. Parental strains 3D1 and 3D7 showed larger differences $(3 \mathrm{D} 1=0.81 \pm 0.03,3 \mathrm{D} 7$ $=0.52 \pm 0.02)$ in the degree of growth inhibition, and their offspring exhibited a wider range in relative growth (0.44-1.13) than the parental strains (Figure 1A and 1B). Only eight offspring in this progeny population had significantly $(\mathrm{p}<0.001)$ higher growth inhibition than 3D1, and no offspring had significantly lower growth inhibition than 3D7. At 8 dpi, only one offspring from the $1 \mathrm{E} 4 \times 1 \mathrm{~A} 5$ cross and five offspring from the $3 \mathrm{D} 1 \times 3 \mathrm{D} 7$ cross did not show growth inhibition under oxidative stress. At 12 dpi, 25 offspring from the $1 \mathrm{E} 4$ x 1 A5 cross and 47 offspring from the 3D1 $\times 3 \mathrm{D} 7$ cross showed an increase in growth under oxidative stress compared to the control (i.e. relative growth was $>1$ ), suggesting a capacity in these offspring to negate the effects of oxidative stress. Weak but significant correlations between growth under control and oxidative stress conditions were found in both segregating populations (Figure 1C), suggesting inherent differences in growth rates among strains irrespective of their environment. Growth in the control environment and growth inhibition under oxidative stress were negatively correlated in both segregating populations (Figure 1D) at both time points, indicating that the strains that grew the fastest in the control environment were the most affected by oxidative stress. 
254 Melanization also decreased significantly (relative gray value $>1$ ) under oxidative stress at 8 dpi in both segregating populations (Figure 1A, middle panel), though four offspring from the 3D1 x 3D7 cross showed increased melanization under oxidative stress. At 12 dpi, 36 progeny from the $1 \mathrm{E} 4 \times 1 \mathrm{~A} 5$ cross and 62 progeny from the $3 \mathrm{D} 1 \times 3 \mathrm{D} 7$ cross became more melanized under oxidative stress (relative gray value $<1$ ), indicating that oxidative stress induced more melanization for those strains at a later stage of growth. To assess how melanin production correlates with colony growth under oxidative stress, simple linear regressions were conducted between relative growth and relative melanization for both time points. A significant negative correlation $(\mathrm{p}<0.01)$ was found between relative gray value and relative growth in both crosses at $8 \mathrm{dpi}$ (Figure 1A, right panel), indicating that a higher reduction in melanization is associated with a higher inhibition in growth under oxidative stress. However, significant correlations between the absolute growth and absolute melanization were also found at 8 dpi for both crosses under both oxidative stress and control conditions (Figure S1), indicating that melanization is associated with growth independent of oxidative stress. In addition, for both crosses under oxidative stress at $12 \mathrm{dpi}$, the strains with an increase in melanization did not consistently show an increase in growth. On the contrary, most of those strains showed decreased growth under oxidative stress (Figure 1A, right panel). These results suggest that melanization is mostly independent of oxidative stress.

273 All traits exhibited high values in broad-sense heritability $(0.98-0.56$, Table S1), indicating that the phenotypic variation among offspring was mainly due to genetic variation. The transgressive segregants for these traits likely resulted from recombination of different alleles among several different genes affecting each trait. 


\section{Genetic architecture of growth and melanization under oxidative stress}

279 To investigate the genetic architectures of growth and melanization in response to oxidative

280 stress, interval mapping using a single-QTL genome scan was performed in the two segregating 281 populations. The permutation analysis for all genome scans resulted in threshold LOD 282 scores ranging between $3.4-3.7$. For the $1 \mathrm{~A} 5 \times 1 \mathrm{E} 4$ cross, genome scans for the colony radius 283 under oxidative stress (orange line) identified four significant QTLs on chromosomes 1, 3, 8 and 12 at $8 \mathrm{dpi}$, three of which were also found at $12 \mathrm{dpi}$ (Figure 2A). QTLs on chromosomes 1 and 12 were not found in the genome scan for colony radius in the control environment (blue line), suggesting that these QTLs are specific for growth under oxidative stress. The chromosome 8 QTL for colony radius under oxidative stress had a much higher LOD score and a narrower confidence interval than the chromosome 8 QTL in the control environment at both time points (Figure 2A), suggesting that the chromosome 8 QTL under oxidative stress may be specifically associated with the oxidative stress environment. Multiple peaks are visible in the LOD plots of the chromosome 8 QTL under control conditions (blue line), which may contribute to the wide confidence interval $(127-430 \mathrm{cM})$ of this QTL. Genome scans for relative colony radius (yellow line) identified two QTLs on chromosome 1 and 8 at 8 dpi, the same QTLs that were identified for colony radius under oxidative stress (Figure 2A). The chromosome 8 QTL for colony radius under oxidative stress at 8 dpi explained $26 \%$ of the phenotypic variation (Table 1A) and resulted in the narrowest $95 \%$ confidence interval at this time point $(203-218 \mathrm{cM})$, which contained only 36 genes (Table 2$)$.

For the 3D7 x 3D1 cross, colony radius under oxidative stress at 8 dpi mapped to two QTLs located on chromosomes 1 and 8, while colony radius at 12 dpi mapped to two QTLs on chromosomes 3 and 11 and a QTL on chromosome 8 that overlapped with the chromosome 8 
control conditions, suggesting it plays a role in oxidative stress tolerance. Relative growth mapped to two weak QTLs on chromosomes 1 and 7, and a large QTL (LOD $=15$ ) on

QTL overlapped with the QTL in the control environment but with a higher LOD score and narrower confidence intervals at both time points, suggesting a higher significance of association for relative growth than for growth in the control environment. This chromosome 10 QTL accounted for $23 \%$ and $16 \%$ of the phenotypic variation in relative growth at 8 and 12 dpi, respectively. The narrowest confidence interval for this chromosome 10 QTL was found at 8 dpi, covering an 8751 bp region that included only 5 genes (Table 1B).

313 The genome scan for melanization under oxidative stress in the $1 \mathrm{~A} 5 \mathrm{x} 1 \mathrm{E} 4$ cross identified four 314 QTLs on chromosomes 2, 3, 8 and 12 at 8 dpi (Figure 3A). All these QTLs, except the 315 chromosome 8 QTL, overlapped with the QTLs found for melanization in the control 316 environment (Table 1A). Relative melanization at 8 dpi mapped to the same QTLs found under 317 control conditions, though the LOD scores were lower (Figure 3A). The relative melanization 318 rate mapped to a large chromosome 3 QTL, the same QTL that was found for melanization under oxidative stress at $12 \mathrm{dpi}$ and in the control environment at $8 \mathrm{dpi}$. The chromosome 8 QTL for melanization under oxidative stress at 8 dpi was the only oxidative stress-specific QTL. This QTL overlapped with the QTL found for growth under oxidative stress at 8 dpi.

In the 3D1 x 3D7 cross, colony melanization under oxidative stress at 8 dpi mapped to QTLs on chromosomes 7 and 8 and relative melanization mapped to QTLs on chromosomes 10 and 11. Only the chromosome 7 QTL did not overlap with QTLs found in the control environment (Figure 3B). Colony melanization at 12 dpi mapped to QTLs on chromosomes 1 and 11 . The chromosome 1 QTL did not overlap with the control environment. The chromosome 11 QTLs 
at 12 dpi were much stronger under oxidative stress than in the control environment. The chromosome 11 QTLs included the PKS1 and Zmrl genes that regulate the production of melanin in Z. tritici (Lendenmann et al. 2014; Krishnan et al. 2018).

To summarize, QTLs specifically associated with growth under oxidative stress were found on chromosomes 1 and 12 in the 1E4 x 1 A5 cross and on chromosomes 1 and 7 in the 3D1 x 3D7 cross. The chromosome 8 QTL in the 1E4 x 1A5 cross covered a narrower interval and had a higher LOD score for growth under oxidative stress than for growth under control conditions, suggesting it may affect growth under oxidative stress. Similarly, the chromosome 10 QTL in the 3D1 x 3D7 cross had a higher LOD score for relative growth than for absolute growth in

338 the control environment, suggesting it may also affect growth under oxidative stress. QTLs found for melanization under oxidative stress largely overlapped with the QTLs found in the control environment, suggesting that these QTLs were not specifically associated with oxidative stress and/or that they showed pleiotropic effects. All unique QTLs (i.e. lacking overlapping confidence intervals) found under oxidative stress conditions were summarized in

343 Table 1, which shows only the QTLs with the narrowest confidence interval in cases where there were overlapping QTLs. Detailed information summarizing all the significant QTLs for each trait are presented in Tables S2 and S3.

\section{Identification of candidate genes within QTL confidence intervals}

348 Only QTLs associated with tolerance to oxidative stress that had a LOD > 10 and confidence

349 intervals containing less than 40 genes were considered for identification of candidate genes.

350 The chromosome 8 QTL for growth under oxidative stress in the 1E4 $\mathrm{x} 1 \mathrm{~A} 5$ cross, the

351 chromosome 10 QTL for relative growth and the chromosome 11 QTL for melanization in the 352 3D1 x 3D7 cross satisfied these criteria. Because the confidence interval of the chromosome 
35311 QTL for melanization in the 3D1 x 3D7 cross overlapped with the previously identified

354 QTL for melanization in the same cross (Lendenmann et al. 2014), we consider this

355 chromosome 11 QTL to be the same QTL reported previously. The candidate genes for this

356 chromosome 11 QTL were already functionally characterized (Krishnan et al. 2018), leading

357 to discovery of polymorphisms affecting transcription of $\mathrm{Zmrl}$ that explained the observed

358 differences in melanization. As we believe that the same polymorphisms can explain the QTL

359 discovered in this independent experiment, we will not discuss this QTL further.

360

361 The chromosome 8 QTL $(\mathrm{LOD}=15.8)$ for colony radius under oxidative stress at 8 dpi in the

362 1A5 x 1E4 cross (Figure 4) contains 36 genes. The marker with the highest LOD is located in a gene 1A5.g8250 (Zt09_8_00185) without a known functional domain (Figure 4C). BLAST analyses to the NCBI database of protein sequences identified eight genes with high similarity to characterized genes in yeast (taxid:4932) (Table 2). Among these genes, glutathione synthetase (1A5.g8249) and Fra1 (1A5.g8239) could potentially affect growth under oxidative stress, according to studies conducted with Saccharomyces cerevisiae (Grant et al. 1997;

368 Kumánovics et al. 2008). Many genes found in this confidence interval have no homology to characterized genes, but are likely to be involved in the cell cycle and/or basic metabolism based on the presence of functional domains associated with DNA repair (1A5.g8253), zinc fingers (1A5.g8255 - 8265) and RNA polymerase (1A5.g8267). A high degree of DNA

372 polymorphisms between the two parental strains, including a transposable element insertion,

373 were found in this confidence interval (Figure 4D). These polymorphisms could affect the expression of genes, protein structures or protein maturation processes.

376 The QTL on chromosome 10 for relative growth at 8 dpi in the 3D1 x 3D7 cross contained 377 only five genes (Figure 5E), including a ferric reductase (3D7.g9787), a major facilitator 
superfamily transporter (MFS, 3D7.g9788), an acetyltransferase (3D7.g9789) and two genes (3D7.g9786 and 3D7.g9790) encoding proteins without known functional domains. BLAST analysis of the protein sequence of the ferric reductase showed that this gene contains a NOX_Duox_like_FAD_NADP domain $(\mathrm{E}$ value $=2.36 \mathrm{e}-43)$ and a ferric reductase domain belonging to the cytochrome $\mathrm{b}$ superfamily $(\mathrm{E}$ value $=4.83 \mathrm{e}-25)$. However, a BLAST analysis between this NOX in Z. tritici and NOXs characterized in other fungi such as NOXB (CAP12517) and NOXA (CAP12516) from Botrytis cinerea (Segmüller et al. 2008) showed low similarity $(E$ value $=5 \mathrm{e}-07$, Identity $=23 \%$, Coverage $=30 \%$, suggesting that this protein represents a previously uncharacterized NOX in fungi. BLAST analysis of the MFS transporter indicated that this gene has a domain similar to a D-galactonate transporter (E value $=3.63 \mathrm{e}-$ 57), which is associated with transport of proteins and carbohydrates. BLAST analysis of the acetyltransferase indicated that it belongs to the acetyltransferase_10 superfamily, which could affect transcriptional elongation. Many polymorphisms were found for the ferric reductase protein sequences among the two parental strains (3D1 and 3D7), in the 5'-UTR of the MFS gene and in the 3'-UTR of the acetyltransferase (Figure 5D and 5E). Four out of the five genes in this confidence interval showed significant differential expression between the two parental strains in yeast sucrose broth (YSB) media (Figure 5F). Gene 3D7.g9786 and the ferric reductase gene were downregulated under starvation conditions, while the MFS and acyltransferase genes were upregulated under starvation conditions (Figure 5F).

\section{In planta expression profile of the candidate genes}

We compared the expression patterns of the candidate genes with known ROS scavengers, including the only known catalase-peroxidases, the only known glutathione peroxidase, four catalases and six SODs in Z. tritici. We also included homologs of the two major regulators of oxidative stress, ZtYapl (Yang et al. 2015) and MgHogl (Mehrabi et al. 2006), and the 
characterized homolog NOXa in Z. tritici (Choi et al. 2016). The expression patterns of the

404 candidate genes in the chromosome 8 and 10 QTLs and selected genes related to ROS

405 elimination (Figure S4) separated them into three groups: highly expressed in the biotrophic (7

406 dpi), necrotrophic (11 and $14 \mathrm{dpi}$ ) or saprotrophic (21 dpi) phase, according to the infection

407 time course shown earlier (Palma-Guerrero et al. 2016). The DNA repair protein (Swi5) in the

408 chromosome 8 QTL and gene 3D7.g9790 in the chromosome 10 QTL showed their highest

409 expression during the early biotrophic phase $(3 \mathrm{dpi})$. The ferric reductase reached its highest

410 expression at $7 \mathrm{dpi}$, together with genes such as catalase 1 (ZtCat1), ZtCpxl and Yapl,

411 matching the timing of the first ROS burst reported in a previous study (Shetty et al. 2003).

412 The gene 3D7.g9786 (without a functional domain), the MFS and the acetyltransferase in the

413 chromosome 10 QTL showed the highest expression at the early necrotrophic phase (11 dpi),

414 together with catalase-peroxidase 2 and glutathione peroxidase. Glutathione synthetase, one of

415 the most compelling candidate genes for the chromosome 8 QTL, showed the highest

416 expression at $14 \mathrm{dpi}$, together with its adjacent gene 1A5.g8250 and two SODs, matching the

417 timing of the second ROS burst reported previously (Shetty et al. 2003). The SODs found in

418 our QTLs showed their highest expression during the saprotrophic phase, together with catalase

\section{DISCUSSION}

422 Tolerance to exogenous oxidative stress is important for most plant pathogens, as it is associated with their pathogenicity and viability during host infection. In this study, we investigated the genetic architecture of this trait in two segregating populations of the fungal wheat pathogen Z. tritici. The large variation found for both growth and melanization in both control and oxidative stress environments were largely explained by genetic variation.

427 Mapping these traits resulted in sixteen significant QTLs without overlapping confidence 428 intervals among the two crosses. Among these 16 QTLs, four were specifically associated with 
the oxidative stress environment. Two other QTLs with high LOD scores were significantly associated with growth under oxidative stress or sensitivity to oxidative stress. A detailed examination of these two QTLs led to identification of candidate genes that may affect oxidative stress tolerance of $Z$. tritici.

\section{Reproducibility of results from independent QTL analyses}

435 In previous QTL mapping investigations oriented around temperature sensitivity (Lendenmann et al. 2016), melanization (Lendenmann et al. 2014) and fungicide tolerance (Lendenmann et al. 2015), the experiments were carried out using PDA media either amended or without

438 fungicides with growth at either 15 or $22{ }^{\circ} \mathrm{C}$. Our study used the same fungal strains and the same culture media purchased from the same company, but with growth at $18^{\circ} \mathrm{C}$. We measured growth and melanization using image analysis as presented in the earlier studies. Hence, we expected to reproduce some of the QTL peaks involved in general regulation of growth and melanization in our study.

444 Four of the QTLs identified in this study were found in similar genomic regions in the earlier studies. The chromosome 8 QTL found for growth in the control environment in the 1E4 x $1 \mathrm{~A} 5$ cross was also found when mapping growth at $15^{\circ} \mathrm{C}$ (Lendenmann et al. 2016). The confidence interval of this QTL overlapped with the confidence intervals of QTLs found for growth at 22 ${ }^{\circ} \mathrm{C}$ (this confidence interval included genes 1A5.g8145-8189) and fungicide sensitivity (this confidence interval included genes 1A5.g8172-8197) (Lendenmann et al. 2015; 2016). The chromosome 10 QTL for relative growth under oxidative stress in the 3D1 x 3D7 cross was also found at a similar position (including genes 3D7.g9787-9790 in this study and genes 3D7.g9793-9801 in the previous study) when mapping for relative growth rate at 15 and $22{ }^{\circ} \mathrm{C}$ 
10 QTL for the relative trait (sensitivity) than for the control environment. Re-mapping of the thermal sensitivity trait of Lendenmann et al. 2016 (which used IPO323 as the reference genome), using our new genetic map (using 3D7 as the reference genome), resulted in the same confidence interval for the chromosome 10 QTL (including genes 3D7.g9787-9789) affecting thermal sensitivity as for the oxidative stress sensitivity trait considered in this study. The chromosome 2 QTL for melanization in the 1E4 x 1A5 cross was also found in the previous mapping for melanization (Lendenmann et al. 2014), with the confidence intervals in the same region (including genes 1A5.g2705-2769 in this study and genes 1A5.g2708-2760 in the previous study). The chromosome 11 QTL found in this study for melanization (including genes 3D7.g10272-10363) overlapped with the chromosome 11 QTL for melanization found in a previous study, which led to the discovery that the $\mathrm{Zmrl}$ gene was regulating the production of melanin (Lendenmann et al 2014; Krishnan et al. 2018).

The reproducibility of QTL peaks between independent studies conducted under similar experimental conditions illustrates the robustness and accuracy of our phenotyping methods.

469 The overlap of growth QTLs under different environmental conditions suggests that these 470 QTLs contain genes that generally regulate growth under many different conditions. But the overlap between QTLs affecting melanization and QTLs affecting growth suggests that there is a connection between these two traits, indicative of pleiotropy and possible tradeoffs. The same pattern was found in earlier studies (Lendenmann et al 2015).

\section{Role of melanization under oxidative stress}

476 Though melanin was suggested to act as a physiological redox buffer that helps protect fungal

477 cells against ROS (Jacobson 2000), to our knowledge no direct empirical evidence was found 478 to support this assumption in fungi. In our study, we compared colony melanization under 
oxidative stress with a control environment and found stress-induced melanization in some decreased melanization (relative gray value $<1$ ) and inhibited growth (relative growth $>1$ ) at hypothesis that melanin increases tolerance to oxidative stress. However, this correlation could simply reflect the correlation between the absolute melanization and absolute growth at 8 dpi in both environments (Figure S1), as the correlations between the relative values were only significant when the correlations between the absolute values were significant. Our finding of overlapping QTLs for relative melanization and melanization in the control environment at 8 dpi (Figure 3A) supports this explanation. We did not find a consistent correlation between increased melanization and increased growth under oxidative stress among the thirty-seven strains from the $1 \mathrm{E} 4 \times 1 \mathrm{~A} 5$ cross that showed ROS-induced melanization (relative gray value melanin does not contribute to higher oxidative stress tolerance.

\section{Growth under oxidative stress}

495 We found weak but significant correlations between growth under oxidative stress and growth 496 in the control environment for both populations (Figure 1C). The highest correlation $\left(\mathrm{R}^{2}=0.25\right)$

497 between these two traits was found in the $1 \mathrm{E} 4 \times 1 \mathrm{~A} 5$ cross at 8 dpi. Closer examination of 498 sixteen strains from this cross exhibiting extremely high (the eight highest) or low (the eight 499 lowest) growth values under oxidative stress showed that the biggest difference in colony size 500 between the two groups of strains was exhibited only under oxidative stress (Figure S2). In 501 addition, differences in colony size in the control environment were also found between the two groups of the strains shown in Figure S2. These results suggest that some of the genes controlling growth under oxidative stress and controlling growth in a non-stressful 
environment are linked or are the same. Overlapping QTLs for growth in the control (Figure 2A). This suggests that both of these chromosome regions carry genes that may play a general role in growth in vitro.

509 In the confidence interval of the chromosome 8 QTL under oxidative stress, we found many genes encoding domains associated with oxidative stress responses as well as general growth

511 (Figure 4D, Table 2). Genes encoding glutathione synthetase, DNA repair protein, zinc fingers

512 and transcription factors were found in this confidence interval. Focusing on the genes in this

513 QTL that are mostly likely to affect oxidative stress tolerance, we considered gene 1A5.g8249

514 (similar to the glutathione synthetase gene (Gsh2) in S. cerevisiae) as one of our top candidates because: (1) Glutathione synthetase was found to affect hydrogen peroxide tolerance in $S$. cerevisiae (Grant et al. 1997), Candida glabrata (Gutiérrez-Escobedo et al. 2013) and Aspergillus nidulans (Bakti et al. 2017), with the depletion of this enzyme resulting in slower growth in $\mathrm{H}_{2} \mathrm{O}_{2}$. (2) Glutathione plays an essential role in maintaining the cellular redox environment (Aquilano et al. 2014; Corso \& Acco 2018), which is important for fungal cell development (Samalova et al. 2013). Glutathione synthetase is one of only two enzymes involved in the synthesis of glutathione and Z. tritici has only one pair of these enzymes in its genome. (3) The glutathione synthetase gene is very close to the peak marker (Figure 4C) and possessed two amino acid polymorphisms in its protein sequence between the two parental strains which could contribute to the observed phenotypic variation. It is also noteworthy that the adjacent gene (1A5.g8250) has 34 amino acid polymorphisms in its protein sequence and that the peak marker resides in this gene. So gene 1A5.g8250 is also a strong candidate for this

527 QTL. But we cannot exclude the possibility that other genes in this QTL encode proteins 528 affecting the oxidative stress response and/or cell growth, such as a peptidase gene (1A5.g8239) 
involved in iron regulon regulation, a gene with a DNA repair protein domain (1A5.g8253)

531 different genes in this confidence interval independently contribute to growth under oxidative stress and growth under non-stressed conditions. Whether it is one gene or several genes in this confidence interval contributing to the variation in growth under oxidative stress will be revealed by future functional studies.

The QTLs on chromosome 1 and chromosome 12 for the $1 \mathrm{E} 4 \times 1 \mathrm{~A} 5$ cross and the QTLs on chromosomes 1 and 7 for the 3D1 x 3D7 cross were specifically associated with oxidative stress. These QTLs encompass homologs of genes known to be involved in oxidative stress

539 tolerance including glutamate-cysteine ligase (3D7.g1830), which is the other enzyme involved in the biosynthesis of glutathione and known to be essential for growth under oxidative stress (Grant et al. 1997; Bakti et al. 2017). Catalase-peroxidase 2 (ZtCpx2, 3D7.g1854) was found to be important in tolerance to high levels of oxidative stress in Z. tritici in a previous study (Gohari A. M. 2015) (Table 1). A large number of genes with unknown

544 functions were also found in these oxidative stress specific QTLs, providing many opportunities to identify new candidate genes related to oxidative stress tolerance. Interestingly, other known ROS regulators such as catalase 1 (ZtCat1, 3D7.g4375) and superoxide dismutase (Cu/Zn SOD 1A5.g3638 and Fe/Mg SOD 1A5.g3652) were found in QTLs that overlapped with QTLs found in the control environment (Table 1). Given the small effects and large

549 confidence intervals of these QTLs, together with the lack of protein polymorphism in the associated SODs and ZtCatl, it is difficult to ascertain whether these genes are involved in the growth under oxidative stress or in non-stressed conditions. Functional studies using these well-known ROS regulators will help to illustrate their effects on oxidative stress tolerance in 
556 The phenotypic data showed a negative correlation between growth inhibition under oxidative stress and growth in the control environment, indicating that strains growing the fastest in the control environment are the most sensitive to oxidative stress. This correlation was strongest in the 3D1 x 3D7 cross at 8 dpi $\left(R^{2}=0.59\right)$ (Figure 1D), suggesting that the large variation in growth inhibition may result from variation in growth under non-stressful conditions. To illustrate this correlation, colony images from the eight segregating strains with the highest relative growth value and eight strains with the lowest relative growth were compared (Figure S3). Bigger differences in colony growth were found in the control environment compared to the oxidative stress environment, supporting our hypothesis that the difference in relative growth largely reflects growth differences under non-stressful conditions. Mapping growth inhibition (measured as relative growth) in the 3D1 x 3D7 cross further supported this hypothesis, as a single QTL $(\mathrm{LOD}=15)$ on chromosome 10 overlapped with the chromosome 10 QTL $($ LOD = 11) found for growth in the control environment (Figure 2B). Because a previous study found that the same QTL was associated with temperature sensitivity

570 (Lendenmann et al. 2016), we postulate that this QTL may include genes that affect sensitivity to several stresses.

Under this hypothesis, we sought candidate genes in the chromosome 10 QTL associated with both fungal growth and stress sensitivity. Among the five genes in the confidence interval

575 (Figure 4C), the ferric reductase with a NOX domain (3D7.g9789) has a function directly related to fungal growth. NOX has been shown to be involved in many fungal developmental processes including cell differentiation, hyphal tip growth and spore germination (Egan et al. 
likely to be highly associated with the colony growth measured in this study. NOX was also reported to be involved in the oxidative stress response in the fungal plant pathogens Botrytis cinerea and Alternaria alternata, where knocking down either NOXA or NOXB resulted in smaller colonies under oxidative stress. A BLAST analysis of the protein sequence of NOXA

583 from $B$. cinerea resulted in gene 3D7.g686 (NOXa) on chromosome 1, which has been characterized as a homolog of NOX1 from M. oryzae and was found to affect virulence in $Z$. tritici (Choi et al. 2016). A BLAST analysis of 3D7.g9789 against other fungal genomes resulted in uncharacterized genes, indicating that this NOX (3D7.g9789) is likely an uncharacterized NOX in fungi with an unknown function. As the 3D7 allele is associated with a higher stress sensitivity than the 3D1 allele (Figure 5B), it is possible that the higher sensitivity of the 3D7 allele reflects differences in the protein sequence of the candidate gene between the two parental strains (Figure 5E). It is also possible that the different phenotypes reflect differential expression of the candidate gene as a result of sequence polymorphisms found in the UTR region (Figure 5E). The RNA expression data of the five candidate genes collected from a previously published study of Z. tritici (Francisco et al. 2019) showed significantly higher expression of the 3D7 allele than the 3D1 allele under both control (YSB) and stress conditions (Figure 5F).

\section{Complex in planta expression of the candidate genes}

598 Plants infected by $Z$. tritici produce ROS during the biotrophic phase $(5-7 \mathrm{dpi})$ and the 599 necrotrophic phase (from around 13 dpi) of infection (Shetty et al. 2003). In our study, we 600 found a correlation between the timing of the first ROS burst and the peak of expression (7 dpi) 601 of genes such as ZtCat1, ZtCpxl and NOX (3D7.g9787), and a correlation between the second 602 burst of ROS and the peak of expression (14 dpi) of genes such as SODs and the glutathione 603 synthetase (Figure S4). These results suggest their possible roles in providing tolerance to 
exogenous ROS from plant defense around 7 dpi and providing tolerance to endogenous ROS

607 the asymptomatic to the necrotrophic phase $(11 \mathrm{dpi})$, which may be correlated with a need to

608 eliminate the large amount of ROS released from dying plant cells (Figure S4). However, the

609 ROS measurements reported in Shetty et al (2003) were performed with a different pathogen

610 strain and host cultivar, which may result in a different timing of this ROS burst. To better

611 understand the roles played by these candidate genes in tolerance to oxidative stress, future

612 studies should consider the effect of different doses of ROS on Z. tritici growth, and conduct

613 additional ROS measurements in planta.

614

\section{CONCLUSION}

616 In this study, we identified genomic regions associated with variation in oxidative stress

617 tolerance using QTL mapping in two crosses of Z. tritici. We found QTLs specific for oxidative

618 stress tolerance, and identified candidate genes that may explain a significant portion of the

619 observed variation. Based on our findings, we hypothesize that genes related to fungal cell 620 growth could also contribute to the variation in oxidative stress tolerance.

\section{ACKNOWLEDGEMENTS}

623 We thank Tiziana Valeria Vonlanthen, Bethan Turnbull, Susanne Dora, Sarah Furler,

624 Alexandra Waltenspühl and Jasmin Wiedmer for helping to conduct experiments. Thanks to

625 Xin Ma and Carolina Francisco for providing the analyzed RNAseq expression data. We are 626 grateful to Andrea Sánchez Vallet and Daniel Croll for critical reading of the manuscript. This 627 research was supported by the Swiss National Science Foundation (31003A_155955 granted 628 to BAM). 
630

631

632

633

634

635

636

637

638

639

640

641

642

643

644

645

646

647

648

649

650

651

652

653

654

\section{Reference}

Aquilano, K., S. Baldelli, and M. R. Ciriolo, 2014 Glutathione: new roles in redox signaling for an old antioxidant. Frontiers in Pharmacology 5(CD000980).

Bakti, F., A. Király, E. Orosz, M. Miskei, T. Emri et al., 2017 Study on the glutathione metabolism of the filamentous fungus Aspergillus nidulans. Acta microbiologica et immunologica Hungarica 64: 255-272.

Bloom, J. S., I. M. Ehrenreich, W. T. Loo, T. L. V. Lite, and L. Kruglyak, 2013 Finding the sources of missing heritability in a yeast cross. Nature 494: 234.

Broman, K. W., and S. Sen, 2009 A Guide to QTL Mapping with R/qtl. Springer, New York.

Broman, K.W., H. Wu, Ś. Sen, and G. A. Churchill, 2003 R/qtl: QTL mapping in experimental crosses. Bioinformatics 19: 889-890.

Broxton, C. N., and V. C. Culotta, 2016 SOD enzymes and microbial pathogens: surviving the oxidative storm of infection. Plos Pathogens 12: p.e1005295.

Chen, D., W. M. Toone, J. Mata, R. Lyne, G. Burns et al., 2003 Global transcriptional responses of fission yeast to environmental stress. Molecular Biology of the Cell 14: 214-229.

Chen, D., C. R. Wilkinson, S. Watt, C. J. Penkett, W. M. Toone et al., 2008 Multiple pathways differentially regulate global oxidative stress responses in fission yeast. Molecular Biology of the Cell 19: 308-317.

Chen, L.-H., S. L. Yang, and K.-R. Chung, 2014 Resistance to oxidative stress via regulating siderophore-mediated iron acquisition by the citrus fungal pathogen Alternaria alternata. Microbiology 160: 970-979.

Choi, Y.-E., C. Lee, and S. B. Goodwin, 2016 Generation of reactive oxygen species via NOXa is important for development and pathogenicity of Mycosphaerella graminicola. Mycobiology 44: 38-47. 
655 Corso, C. R. and A. Acco, 2018. Glutathione system in animal model of solid tumors: From regulation to therapeutic target. Critical reviews in oncology/hematology 128: 43-57.

657 Covarrubias-Pazaran, G., 2016 Genome-assisted prediction of quantitative traits using the R package sommer. PloS one 11: p.e0156744.

Doehlemann, G., and C. Hemetsberger, 2013 Apoplastic immunity and its suppression by filamentous plant pathogens. New Phytologist 198: 1001-1016.

661 Egan, M. J., Z.-Y. Wang, M. A. Jones, N. Smirnoff, and N. J. Talbot, 2007 Generation of reactive oxygen species by fungal NADPH oxidases is required for rice blast disease. Proceedings of the National Academy of Sciences of the United States of America 104: $11772-11777$.

Fernandez, J. and R. A. Wilson, 2014 Characterizing roles for the glutathione reductase, thioredoxin reductase and thioredoxin peroxidase-encoding genes of Magnaporthe oryzae during rice blast disease. Plos One 9: p.e87300.

Francisco, C. S., X. Ma, M. M. Zwyssig, B. A. McDonald, and J. Palma-Guerrero, 2019 Morphological changes in response to environmental stresses in the fungal plant pathogen Zymoseptoria tritici. Scientific reports 9: 9642.

Gocheva, Y. G., S. Tosi, E. Tz. Krumova, L. S. Slokoska, J. G. Miteva et al., 2009 Temperature downshift induces antioxidant response in fungi isolated from Antarctica. Extremophiles 13: 273-281.

Gohari, A. M., 2015. Functional analysis of catalase-peroxidase encoding genes in the fungal wheat pathogen Zymoseptoria tritici. PhD Thesis, Chapter 5.

Grant, C. M., F.H. MacIver, and I.W. Dawes, 1997 Glutathione synthetase is dispensable for growth under both normal and oxidative stress conditions in the yeast Saccharomyces cerevisiae due to an accumulation of the dipeptide gamma-glutamylcysteine. Molecular Biology of the Cell 8: 1699-1707. 
680 Gutiérrez-Escobedo, G., E. Orta-Zavalza, I. Castaño, and D. L. P. Alejandro, 2013 Role of 681 glutathione in the oxidative stress response in the fungal pathogen Candida glabrata. Current Genetics 59: 91-106.

683

684

685

686

687

688

689

690

691

692

693

694

695

696

697

698

699

700

701

702

Heller, J. and P. Tudzynski, 2011 Reactive oxygen species in phytopathogenic fungi: signaling, development and disease. Annual Review of Phytopathology 49: 369-390.

Hothorn, T., F. Bretz, and P. Westfall, 2008 Simultaneous inference in general parametric models. Biometrical Journal: Journal of Mathematical Methods in Biosciences 50: 346363.

Jacobson, E. S., 2000. Pathogenic Roles for Fungal Melanins. Clinical Microbiology Reviews 13: 708-717.

Johansen-Morris, A. D. and R.G. Latta, 2006 Fitness consequences of hybridization between ecotypes of Avena barbata: hybrid breakdown, hybrid vigor, and transgressive segregation. Evolution 60: 1585-1595.

Krishnan, P., L. Meile, C. Plissonneau, X. Ma, F. E. Hartmann, D. Croll et al., 2018 Transposable element insertions shape gene regulation and melanin production in a fungal pathogen of wheat. BMC Biology 16: 231.

Kumánovics, A., O. Chen, L. Li, D. Bagley, E. M. Adkins et al., 2008. Identification of FRA1 and FRA2 as genes involved in regulating the yeast iron regulon in response to decreased mitochondrial iron-sulfur cluster synthesis. The Journal of Biological Chemistry 283:10276-10286.

Lendenmann, M. H., D. Croll, E. L. Stewart and B. A. McDonald, 2014 Quantitative trait locus mapping of melanization in the plant pathogenic fungus Zymoseptoria tritici. G3 4: 2519-2533. 
703 Lendenmann, M. H., D. Croll, and B. A. McDonald, 2015 QTL mapping of fungicide sensitivity reveals novel genes and pleiotropy with melanization in the pathogen Zymoseptoria tritici. Fungal Genetics and Biology 80: 53-67.

Lendenmann, M. H., D. Croll, J. Palma-Guerrero, E. L. Stewart, and B. A. McDonald, 2016 QTL mapping of temperature sensitivity reveals candidate genes for thermal adaptation and growth morphology in the plant pathogenic fungus Zymoseptoria tritici. Heredity 116: 384-394.

Lin, C.-H., S. L. Yang, and K.-R. Chung, 2009 The YAP1 homolog-mediated oxidative stress tolerance is crucial for pathogenicity of the necrotrophic fungus Alternaria alternata in citrus. Molecular Plant-Microbe Interactions 22: 942-952.

Ma, H., M. Wang, Y. Gai, H. Fu, B. Zhang et al., 2018 Thioredoxin and glutaredoxin systems required for oxidative stress resistance, fungicide sensitivity, and virulence of Alternaria alternata. Applied and Environmental Microbiology 84: 369.

Mehrabi, R., L. H. Zwiers, M. A. de Waard, G. H. Kema, 2006 MgHogl regulates dimorphism avirulence factor encoded in a highly plastic genomic region triggers partial resistance to septoria tritici blotch. New Phytologist 219: 1048-1061.

Molina, L. and R. Kahmann, 2007 An Ustilago maydis gene involved in $\mathrm{H}_{2} \mathrm{O}_{2}$ detoxification is required for virulence. The Plant Cell 19: 2293-2309. transcriptome analyses in Zymoseptoria tritici reveal significant differences in gene expression among strains during plant infection. Molecular Plant-Microbe Interactions 30: 231-244. 
Palma-Guerrero, J., S. F. Torriani, M. Zala, D. Carter, M. Courbot et al., 2016 Comparative transcriptomic analyses of Zymoseptoria tritici strains show complex lifestyle transitions and intraspecific variability in transcription profiles. Molecular Plant Pathology 17: 845-859.

Papadakis, M. A. and C. T. Workman, 2014 Oxidative stress response pathways: Fission yeast as archetype. Critical Reviews in Microbiology 41: 520-535.

Plissonneau, C., F. E. Hartmann, and D. Croll, 2018 Pangenome analyses of the wheat pathogen Zymoseptoria tritici reveal the structural basis of a highly plastic eukaryotic genome., BMC Biology 16: p.5.

Rolke, Y., S. Liu, T. Quidde, B. Williamson, A. Schouten et al., 2004 Functional analysis of $\mathrm{H} 2 \mathrm{O} 2$-generating systems in Botrytis cinerea: the major $\mathrm{Cu}-\mathrm{Zn}$-superoxide dismutase (BCSOD1) contributes to virulence on French bean, whereas a glucose oxidase (BCGOD1) is dispensable. Molecular Plant Pathology 5: 17-27.

Ronen, M., S. Shalaby, and B. A. Horwitz, 2013 Role of the transcription factor ChAP1 in cytoplasmic redox homeostasis: imaging with a genetically encoded sensor in the maize pathogen Cochliobolus heterostrophus. Molecular Plant Pathology 14: 786-790.

Ryder, L. S., Y. F. Dagdas, T. A. Mentlak, M. J. Kershaw, C. R. Thornton et al., 2013 NADPH oxidases regulate septin-mediated cytoskeletal remodeling during plant infection by the rice blast fungus. Proceedings of the National Academy of Sciences of the United States of America 110: 3179-3184.

Samalova, M., A. J. Meyer, S. J. Gurr, and M. D. Fricker, 2013 Robust anti-oxidant defences in the rice blast fungus Magnaporthe oryzae confer tolerance to the host oxidative burst. New Phytologist 201: 556-573.

Sanchez-Vallet, A., M. C. McDonald, P. S. Solomon, B. A. McDonald, 2015 Is Zymoseptoria tritici a hemibiotroph? Fungal Genetics and Biology 79: 29-32. 
Segal, L. M. and R. A. Wilson, 2018 Reactive oxygen species metabolism and plant-fungal interactions. Fungal Genetics and Biology 110: 1-9.

Segmüller, N., U. Ellendorf, B. Tudzynski, P. Tudzynski, 2007. BcSAK1, a stress-activated mitogen-activated protein kinase, is involved in vegetative differentiation and pathogenicity in Botrytis cinerea. Eukaryotic Cell 6: 211-221.

Segmüller, N., L. Kokkelink, S. Giesbert, D. Odinius, J. van Kan, and P. Tudzynski, 2008 NADPH oxidases are involved in differentiation and pathogenicity in Botrytis cinerea. Molecular Plant-Microbe Interactions 21: 808-819.

Shetty, N. P., B. K. Kristensen, M.-A. Newman, K. Møller, P. L. Gregersen et al., 2003 Association of hydrogen peroxide with restriction of Septoria tritici in resistant wheat. Physiological and Molecular Plant Pathology 62: 333-346.

Shetty, N. P., R. Mehrabi, H. Lütken, A. Haldrup, G. H. Kema et al., 2007 Role of hydrogen peroxide during the interaction between the hemibiotrophic fungal pathogen Septoria tritici and wheat. New Phytologist 174: 637-647.

Thorpe, G. W., C. S. Fong, N. Alic, V. J. Higgins, and I. W. Dawes, 2004 Cells have distinct mechanisms to maintain protection against different reactive oxygen species: Oxidative-stress-response genes. Proceedings of the National Academy of Sciences of the United States of America 101: 6564-6569.

Torriani, S. F. F., J. P. Melichar, C. Mills, N. Pain, H. Sierotzki, M. Courbot, 2015 Zymoseptoria tritici: A major threat to wheat production, integrated approaches to control. Fungal Genetics and Biology 79: 8-12.

Trachootham, D., W. Lu, M. A. Ogasawara, R. D. Nilsa, and P. Huang, 2008 Redox regulation of cell survival. Antioxidants \& Redox Signaling 10: 1343-1374.

Walia, A. and R. Calderone, 2008 The SSK2 MAPKKK of Candida albicans is required for oxidant adaptation in vitro. Fems Yeast Research 8: 287-299. 
778 Yang, F., W. Li, M. Derbyshire, M. R. Larsen, J. J. Rudd et al., 2015 Unraveling incompatibility between wheat and the fungal pathogen Zymoseptoria tritici through apoplastic proteomics. BMC Genomics 16: p.178.

781 Yang, S. L., P.-L. Yu, and K.-R. Chung, 2016 The glutathione peroxidase-mediated reactive oxygen species resistance, fungicide sensitivity and cell wall construction in the citrus fungal pathogen Alternaria alternata. Environmental Microbiology 18: 923-935.

784 Yu, P.-L., C. L. Wang, P. Y. Chen, M. H. Lee, 2017 YAP1 homologue-mediated redox sensing is crucial for a successful infection by Monilinia fructicola. Molecular Plant Pathology 18: 783-797.

787 Zhong, Z., T. C. Marcel, F. E. Hartmann, X. Ma, C. Plissonneau, et al., 2017 A small secreted protein in Zymoseptoria tritici is responsible for avirulence on wheat cultivars carrying the Stb6 resistance gene. New Phytologist 214: 619-631.

790 
Table 1. Summary of the non-overlapping QTLs with the narrowest confidence intervals associated with colony growth and melanization under oxidative stress.

A

\begin{tabular}{|c|c|c|c|c|c|c|c|c|c|}
\hline Cross & Trait & Chr & Highest LOD & Dpi & Var. (\%) & $\mathrm{Cl}$ (bp) & No. genes & Possible candidates & Control \\
\hline & Colony Radius & 1 & 4.49 & 8 & 10.04 & $1917295-2665777$ & 284 & & No \\
\hline & Relative Melanization & 1 & 3.97 & 8 & 4.96 & $262715-733242$ & 136 & & Yes \\
\hline & Relative Melanization & 2 & 11.11 & 8 & 15.77 & $1589560-1793667$ & 67 & & Yes \\
\hline & Colony Radius & 3 & 6.38 & 8 & 5.22 & $465107-1344743$ & 231 & $\begin{array}{c}\mathrm{Cu} / \mathrm{Zn} \mathrm{SOD}, \mathrm{Fe} / \mathrm{Mg} \\
\text { SOD }\end{array}$ & Yes \\
\hline \multirow[t]{4}{*}{$1 \mathrm{E} 4 \times 1 \mathrm{~A} 5$} & Melanization & 6 & 3.67 & 12 & 5.84 & $1041770-1583118$ & 165 & & No \\
\hline & Colony Radius & 8 & 15.82 & 8 & 24.90 & $496559-578252$ & 35 & & Yes \\
\hline & Relative Melanization & 8 & 7.45 & 8 & 9.51 & $114401-346112$ & 78 & $\begin{array}{l}\text { Glucose-6-phosphate 1- } \\
\text { dehydrogenase (zwf1) }\end{array}$ & Yes \\
\hline & Relative Growth Rate & 12 & 5.74 & $8-12$ & 4.42 & $1110580-1334901$ & 82 & $\begin{array}{c}\text { Tyrosine protein } \\
\text { phosphatase (yvh1) }\end{array}$ & No \\
\hline
\end{tabular}




\begin{tabular}{|c|c|c|c|c|c|c|c|c|c|}
\hline Cross & Trait & Chr & Highest LOD & Dpi & Var. (\%) & $\mathrm{Cl}(\mathrm{bp})$ & No. genes & Possible candidates & Control \\
\hline & Colony Radius & 1 & 5.59 & 8 & 8.96 & $1246555-2072715$ & 262 & Catalase-peroxidase (ZtCpx2) & No \\
\hline & Relative Radius & 1 & 4.86 & 8 & 8.09 & $5256728-5576484$ & 104 & Glutaredoxin & No \\
\hline & Colony Radius & 3 & 5.63 & 12 & 6.53 & $2983747-3365135$ & 135 & Catalase (ZtCat1) & Yes \\
\hline & Relative Radius & 7 & 3.68 & 8 & 4.83 & $1363626-1930081$ & 201 & & No \\
\hline \multirow[t]{5}{*}{$3 D 1 \times 3 D 7$} & Melanization & 7 & 4.31 & 8 & 7.20 & $529943-652007$ & 50 & Trehalose-phosphatase & No \\
\hline & Colony Radius & 8 & 3.83 & 12 & 9.72 & 843926-1221280 & 157 & Catalase-peroxidase $(Z t C p \times 1)$ & Yes \\
\hline & Relative Radius & 10 & 14.85 & 8 & 21.06 & 749521-758289 & 5 & & Yes \\
\hline & Relative Growth Rate & 10 & 4.53 & 8-12 & 7.30 & 804952-1126067 & 124 & & No \\
\hline & Melanization & 11 & 9.82 & 12 & 14.33 & $514048-879885$ & 126 & $P K S 1, Z m r 1$ & Yes \\
\hline
\end{tabular}

$\overline{\mathrm{Chr}}=$ chromosome, $\mathrm{Dpi}=$ Days post inoculation, Var. = variation explained by the QTL, $\mathrm{Cl}=$ Confidence interval, Control = Overlaps with QTLs found in the control environment. 
Table 2. Genes found within the QTL confidence interval on chromosome 8 for growth under oxidative stress at 8 dpi in the $1 E 4 \times 1$ A5 cross.

\begin{tabular}{|c|c|c|c|c|c|c|c|c|c|}
\hline \multirow{2}{*}{$\begin{array}{c}1 A 5 \\
\text { Gene ID }\end{array}$} & \multirow{2}{*}{$\begin{array}{l}\text { IPO323 } \\
\text { Gene ID }\end{array}$} & \multirow{2}{*}{ IPR_description } & \multicolumn{2}{|c|}{ Protein polymorphism } & \multicolumn{5}{|c|}{ Homology to Saccharomyces cerevisiae } \\
\hline & & & Percentage & $\begin{array}{c}\text { Amino } \\
\text { Acid }\end{array}$ & Gene & Coverage & E value & Identity & Description \\
\hline $1 \mathrm{~A} 5.98236$ & NA & $\begin{array}{l}\text { Lipase, GDXG, } \\
\text { putative serine } \\
\text { active site, } \\
\text { Alpha/Beta } \\
\text { hydrolase fold }\end{array}$ & $<1 \%$ & 3 & & & & & \\
\hline 1A5.g8237 & 8_00172 & $\begin{array}{l}\text { Zinc finger, } \\
\text { MYND-type }\end{array}$ & - & $\begin{array}{l}\text { very } \\
\text { polymor } \\
\text {-phic }\end{array}$ & & & & & \\
\hline 1A5.g8238 & 8_00173 & $\begin{array}{c}\text { Arginine } \\
\text { biosynthesis } \\
\text { protein ArgJ }\end{array}$ & $2 \%$ & 10 & Arg7p & $93 \%$ & $\begin{array}{l}5.00 \mathrm{E}- \\
132\end{array}$ & $45.81 \%$ & $\begin{array}{l}\text { Ornithine acetyltransferase, } \\
\text { involved in ornithine biosynthesis. }\end{array}$ \\
\hline 1A5.g8239 & 8_00174 & $\begin{array}{l}\text { Peptidase M24, } \\
\text { Creatinase }\end{array}$ & $2 \%$ & 11 & Fra1p & $99 \%$ & 0 & $44.02 \%$ & $\begin{array}{l}\text { Involved in the regulation of the } \\
\text { iron regulon in responses to } \\
\text { decreased mitochondrial iron- } \\
\text { sulfur cluster synthesis. }\end{array}$ \\
\hline $1 \mathrm{~A} 5.98240$ & 8_00175 & $\begin{array}{c}\text { Catechol } \\
\text { dioxygenase, } \\
\text { Intradiol ring- } \\
\text { cleavage } \\
\text { dioxygenase }\end{array}$ & $<1 \%$ & 2 & & & & & \\
\hline 1A5.g8241 & 8_00176 & NA & - & $\begin{array}{l}\text { Another } \\
298 \text { aa } \\
\text { more in } \\
1 \mathrm{E} 4\end{array}$ & & & & & \\
\hline
\end{tabular}




\begin{tabular}{|c|c|c|c|c|c|c|c|c|c|}
\hline 1A5.g8242 & 8_00177 & $\begin{array}{c}\text { NADPH- } \\
\text { dependent FMN } \\
\text { reductase-like, } \\
\text { Arsenate } \\
\text { resistance ArsH, } \\
\text { Flavoprotein-like } \\
\text { domain }\end{array}$ & $0 \%$ & & & & & & \\
\hline 1A5.g8243 & 8_00178 & $\begin{array}{c}\text { Zinc finger, } \\
\text { double-stranded } \\
\text { RNA binding, } \\
\text { Splicing factor 3A } \\
\text { subunit 3, C2H2- } \\
\text { type }\end{array}$ & $<1 \%$ & 1 & Prp9p & $76 \%$ & $\begin{array}{c}3.00 \mathrm{E}- \\
49\end{array}$ & $30.05 \%$ & $\begin{array}{l}\text { Necessary for binding of the U2 } \\
\text { snRNP to the pre-mRNA in an } \\
\text { early step of spliceosome } \\
\text { assembly. }\end{array}$ \\
\hline 1A5.g8244 & 8_00179 & $\begin{array}{l}\text { ATP-dependent } \\
\text { RNA helicase } \\
\text { DEAD-box }\end{array}$ & $0 \%$ & & Fal1p & $98 \%$ & 0 & $64.30 \%$ & $\begin{array}{c}\text { Involved in } 40 \text { S ribosomal subunit } \\
\text { biogenesis. }\end{array}$ \\
\hline 1A5.g8245 & 8_00180 & $\begin{array}{l}\text { Peptidyl-tRNA } \\
\text { hydrolase }\end{array}$ & $6 \%$ & $\begin{array}{l}14(+2 \\
\text { indels })\end{array}$ & Pth1p & $64 \%$ & $\begin{array}{c}9.00 \mathrm{E}- \\
12\end{array}$ & $34.68 \%$ & \\
\hline 1A5.g8246 & 8_00181 & $\begin{array}{l}\text { Winged helix-turn- } \\
\text { helix DNA-binding } \\
\text { domain }\end{array}$ & $0 \%$ & & & & & & \\
\hline 1A5.g8247 & 8_00182 & $\begin{array}{l}\text { TB2/DP1/HVA22- } \\
\text { related protein }\end{array}$ & $0 \%$ & 0 & $\begin{array}{c}\text { Yop1 } \\
\mathrm{p}\end{array}$ & $90 \%$ & $\begin{array}{c}3.00 \mathrm{E}- \\
34\end{array}$ & $39.63 \%$ & $\begin{array}{c}\text { Involved in membrane/vesicle } \\
\text { trafficking. }\end{array}$ \\
\hline 1A5.g8248 & 8_00183 & $\begin{array}{l}\text { SNF2-related, P- } \\
\text { loop containing } \\
\text { nucleoside } \\
\text { triphosphate } \\
\text { hydrolase, Sterile } \\
\text { alpha } \\
\text { motif/pointed } \\
\text { domain, Helicase } \\
\text { superfamily } 1 / 2, \\
\text { ATP-binding } \\
\text { domain }\end{array}$ & $1 \%$ & 3 & & & & & \\
\hline
\end{tabular}




\begin{tabular}{|c|c|c|c|c|c|c|c|c|c|}
\hline 1A5.g8249 & 8_00184 & $\begin{array}{l}\text { Glutathione } \\
\text { synthase }\end{array}$ & $1 \%$ & 2 & $\begin{array}{c}\text { Gsh2 } \\
\mathrm{p}\end{array}$ & $98 \%$ & $\begin{array}{c}1.00 \mathrm{E}- \\
122\end{array}$ & $40.97 \%$ & $\begin{array}{l}\text { Involved in step } 2 \text { of the } \\
\text { biosynthesis of glutathione. }\end{array}$ \\
\hline 1A5.g8250 & 8_00185 & $\begin{array}{c}\text { Domain of } \\
\text { unknown function } \\
\text { DUF4203 }\end{array}$ & $3 \%$ & 34 & & & & & \\
\hline 1A5.g8251 & 8_00186 & $\begin{array}{l}\text { Uncharacterized } \\
\text { protein family } \\
\text { UPF0642 }\end{array}$ & $<1 \%$ & 1 & & & & & \\
\hline 1A5.g8252 & 8_00187 & $\begin{array}{l}\text { Zinc finger, MIZ- } \\
\text { type, E3 SUMO } \\
\text { protein ligase, } \\
\text { SAP domain, } \\
\text { PINIT domain } \\
\end{array}$ & $0 \%$ & 0 & & & & & \\
\hline 1A5.g8253 & 8_00188 & $\begin{array}{l}\text { DNA repair } \\
\text { protein, Swi5 }\end{array}$ & $7 \%$ & 13 & & & & & \\
\hline 1A5.g8254 & 8_00189 & $\begin{array}{c}\text { Domain of } \\
\text { unknown function } \\
\text { DUF2427 }\end{array}$ & $<1 \%$ & 3 & Ytp1p & $62 \%$ & $\begin{array}{l}3.00 \mathrm{E}- \\
69\end{array}$ & $41.69 \%$ & $\begin{array}{l}\text { Can function as a molecular } \\
\text { chaperone, and controls proteins } \\
\text { involved in metabolism, stress } \\
\text { response, and DNA regulation. }\end{array}$ \\
\hline 1A5.g8255 & 8_00190 & $\begin{array}{l}\text { Zinc finger, } \\
\text { MYND-type }\end{array}$ & $<1 \%$ & 3 & & & & & \\
\hline 1A5.g8256 & 8_00191 & $\begin{array}{l}\text { Zinc finger, } \\
\text { MYND-type }\end{array}$ & $3 \%$ & 6 & & & & & \\
\hline 1A5.g8257 & 8_00192 & $\begin{array}{l}\text { Zinc finger, } \\
\text { MYND-type }\end{array}$ & $<1 \%$ & 1 & & & & & \\
\hline 1A5.g8258 & 8_00193 & $\begin{array}{l}\text { Zinc finger, } \\
\text { MYND-type }\end{array}$ & $17 \%$ & $\begin{array}{l}31(+4 \\
\text { indels) }\end{array}$ & & & & & \\
\hline 1A5.g8259 & 8_00194 & $\begin{array}{l}\text { Zinc finger, } \\
\text { MYND-type }\end{array}$ & $5 \%$ & 10 & & & & & \\
\hline 1A5.g8260 & 8_00195 & - & $>50 \%$ & $\begin{array}{l}\text { very } \\
\text { polymor } \\
\text {-phic }\end{array}$ & & & & & \\
\hline
\end{tabular}




\begin{tabular}{|c|c|c|c|c|c|c|c|c|c|}
\hline 1A5.g8261 & NA & $\begin{array}{l}\text { Zinc finger, } \\
\text { MYND-type }\end{array}$ & $>50 \%$ & $\begin{array}{l}\text { very } \\
\text { polymor } \\
\text {-phic }\end{array}$ & & & & & \\
\hline 1A5.g8262 & NA & $\begin{array}{l}\text { Zinc finger, } \\
\text { MYND-type }\end{array}$ & $<1 \%$ & 2 & & & & & \\
\hline 1A5.g8263 & NA & - & $>50 \%$ & $\begin{array}{l}\text { very } \\
\text { polymor } \\
\text {-phic }\end{array}$ & & & & & \\
\hline 1A5.g8264 & NA & $\begin{array}{l}\text { Zinc finger, } \\
\text { MYND-type }\end{array}$ & $0 \%$ & 0 & & & & & \\
\hline 1A5.g8265 & 8_00199 & $\begin{array}{l}\text { Zinc finger, } \\
\text { MYND-type }\end{array}$ & $<1 \%$ & 2 & & & & & \\
\hline 1A5.g8266 & 8_00200 & $\begin{array}{l}\text { Sec8 exocyst } \\
\text { complex } \\
\text { component } \\
\text { specific domain }\end{array}$ & $0 \%$ & 0 & $\begin{array}{c}\text { Sec8 } \\
p\end{array}$ & $89 \%$ & $\begin{array}{c}4.00 \mathrm{E}- \\
55\end{array}$ & $22.26 \%$ & $\begin{array}{l}\text { Involved in the docking of exocytic } \\
\text { vesicles with fusion sites on the } \\
\text { plasma membrane. Some alleles } \\
\text { of this gene are temperature } \\
\text { sensitive. }\end{array}$ \\
\hline 1A5.g8267 & 8_00201 & $\begin{array}{l}\text { Tetratricopeptide } \\
\text { repeat }\end{array}$ & $<1 \%$ & 1 & Ctr9p & $90 \%$ & $\begin{array}{c}1.00 \mathrm{E}- \\
102\end{array}$ & $27.56 \%$ & $\begin{array}{l}\text { Involved in transcription initiation } \\
\text { and elongation. Also has a role in } \\
\text { transcription-coupled histone } \\
\text { modification and chromosome } \\
\text { segregation. }\end{array}$ \\
\hline 1A5.g8268 & 8_00202 & $\begin{array}{c}\mathrm{Zn}(2)-\mathrm{C} 6 \text { fungal- } \\
\text { type DNA-binding } \\
\text { domain }\end{array}$ & $<1 \%$ & 4 & & & & & \\
\hline 1A5.g8269 & 8_00203 & $\begin{array}{l}\text { Pyruvate kinase- } \\
\text { like, Molybdenum } \\
\text { cofactor } \\
\text { sulfurase, } \mathrm{C}- \\
\text { terminal, } \mathrm{N}- \\
\text { terminal beta } \\
\text { barrel } \\
\end{array}$ & $<1 \%$ & 1 & & & & & \\
\hline 1A5.g8270 & NA & - & $<1 \%$ & 1 & & & & & \\
\hline
\end{tabular}




\begin{tabular}{|c|c|c|c|c|c|c|c|c|c|}
\hline 1A5.g8271 & 8_00204 & $\begin{array}{l}\mathrm{Zn}(2)-\mathrm{C} 6 \text { fungal- } \\
\text { type DNA-binding } \\
\text { domain }\end{array}$ & $<1 \%$ & 4 & $\begin{array}{c}\text { Upc2 } \\
p\end{array}$ & $82 \%$ & $\begin{array}{c}1.00 \mathrm{E}- \\
11\end{array}$ & $24.52 \%$ & $\begin{array}{l}\text { Involved in activation of anaerobic } \\
\text { genes, sterol uptake and } \\
\text { regulation of the sterol } \\
\text { biosynthesis. }\end{array}$ \\
\hline
\end{tabular}

Note: protein sequences were compared between the $1 \mathrm{~A} 5$ and $1 \mathrm{E} 4$ strains. Polymorphism $<=1 \%$ appear as $1 \%$. The amino acid substitutions were not counted for genes with polymorphism $>50 \%$. Aa $=$ amino acids, indels $=$ insertions and deletions. 
Figure 1. Variation in growth and in melanization under oxidative stress. (A) The distribution of the relative growth (left panels) and relative melanization (middle panels) traits in the $1 \mathrm{E} 4 \times 1 \mathrm{~A} 5$ cross and the 3D1 x 3D7 cross. Relative colony radius ( $\mathrm{x}$ axis) less than 1 indicates that oxidative stress inhibited the growth, and vice versa. Relative melanization value ( $\mathrm{x}$ axis) less than 1 indicates more melanization under oxidative stress. The dashed line stands for 1 , indicating that the value under oxidative condition equals the value under the control condition. The linear correlations between relative growth and relative melanization are shown in the right panel. (B) Phenotypes of the parental strains under control conditions and under oxidative stress. (C) Significant correlations between growth in the control condition and growth under oxidative stress at 8 dpi. (D) Significant correlation between relative growth and growth under control conditions at 8 dpi.

Figure 2. Genetic architecture of growth-related traits. (A) Interval mapping for the 1E4 x $1 \mathrm{~A} 5$ cross. (B) Interval mapping for the 3D1 x 3D7 cross. The blue line shows the mapping results for colony radius under control conditions, the orange line shows the mapping results for colony radius under oxidative stress and the yellow line shows the mapping results for relative growth. The vertical axis shows the $\log 10$ likelihood ratio (LOD score), and the horizontal axis indicates the chromosome number. The horizontal dashed lines in the figure indicate the LOD threshold estimated from 1000 permutations of the genome-wide scan.

Figure 3. Genetic architecture of melanization-related traits. (A) Interval mapping for the $1 \mathrm{E} 4 \times 1 \mathrm{~A} 5$ cross. (B) Interval mapping for the 3D1 x 3D7 cross. The blue line presents the mapping results for colony melanization under control conditions, the orange line presents 
the mapping results for colony melanization under oxidative stress and the yellow line presents the mapping results for relative melanization. The vertical axis shows the log 10 likelihood ratio (LOD score), and the horizontal axis indicates the chromosome number. The horizontal dashed lines in the figure indicate the LOD threshold estimated from 1000 permutations of the genome-wide scan.

\section{Figure 4. The chromosome 8 QTL for growth under oxidative stress in the $1 \mathrm{E} 4 \times 1 \mathrm{A5}$}

cross. (A) LOD plot of the chromosome 8 QTL for growth under oxidative stress at 8 dpi. The $\mathrm{y}$ axis indicates the LOD score, and the $\mathrm{x}$ axis indicates the genetic distance (centiMorgans) along the chromosome. The red arrow indicates the marker with the highest LOD, which resides at 534204 bp for growth at 8 dpi. The 95\% Bayesian confidence interval is shown below the LOD plot. (B) Allele effect of the chromosome 8 QTL: individuals with the 1 A5 allele at 534204 bp have a smaller colony radius under oxidative stress than individuals with the 1E4 allele at 534204 bp. Each closed circle represents a different offspring. (C) SNP markers in the confidence intervals are shown as vertical lines. The red arrow indicates the location of the marker with the highest LOD. (D) Synteny plot showing the DNA polymorphisms in this genomic region. The red segments indicate regions with sequence identity greater than $90 \%$. The darker the red color, the lower the degree of polymorphism in the genomic region. The arrows represent genes, and the blue block represents a transposable element. (E) Functional domains in the 36 genes within the confidence interval. Details for these genes are presented in Table 2. 
Figure 5. The chromosome 10 QTL for relative growth at $8 \mathrm{dpi}$ in the 3D1 $\mathrm{x} 3 \mathrm{D} 7$ cross.

(A) LOD curve of the chromosome 10 QTL. The red arrow indicates the peak marker (chr10_755324). (B) Allele effects at the marker Chr10_755324: individuals with 3D1 allele showed higher average relative growth than individuals with the 3D7 allele. Each closed circle represents an individual. (C) Markers in the confidence interval of this QTL. Red arrow indicates the peak marker. (D) Synteny plot of the confidence interval region between the two parental strains. The darker the red color, the lower the degree of polymorphism in the genomic region. (E) The gene ID in 3D7, the corresponding gene ID in IPO323, the functional domains and the gene polymorphisms associated with (D). Polymorphism numbers indicate the number of substitutions, and indels indicate the number of nucleotides missing in one of the parental strains. The number in brackets indicates the percentage of polymorphic amino acids in the entire protein. (F) Expression values in reads per kilobase of transcript per million mapped reads (RPKM) of the five genes in yeast sucrose broth medium (YSB, control), minimal medium (starvation) and in planta infection at $7 \mathrm{dpi}$. The expression data were collected from three replicates in a previous study (Francisco et al. 2018). 
bioRxiv preprint doi: https://doi.org/10.1101/2020.02.20.957431; this version posted February 20, 2020. The copyright holder for this

preprint (which was not certified by peer review) is the author/funder. All rights reserved. No reuse allowed without permission. 
A
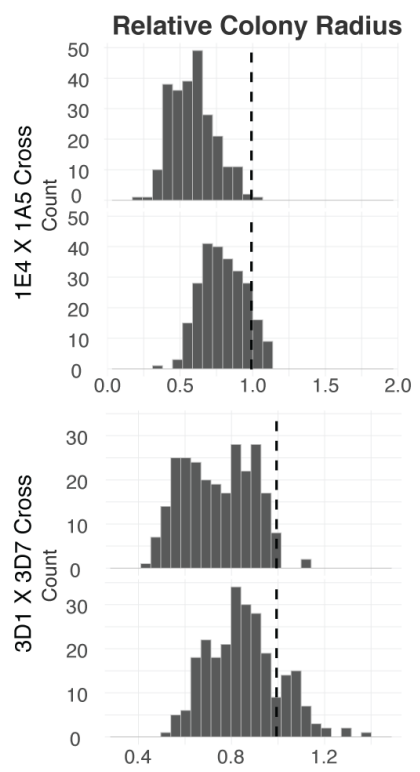
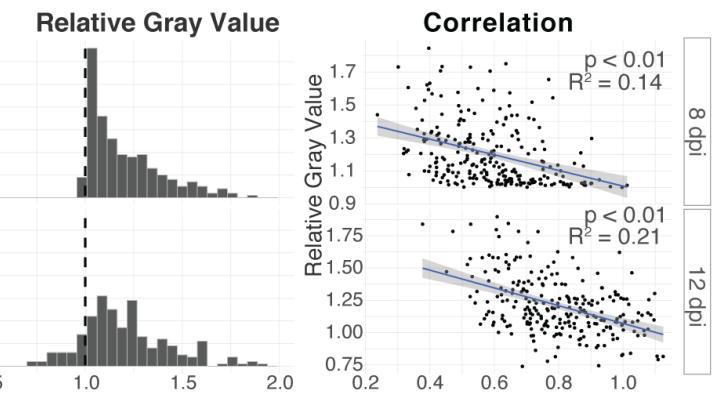

C Correlation

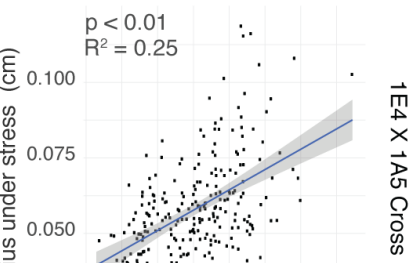

苋
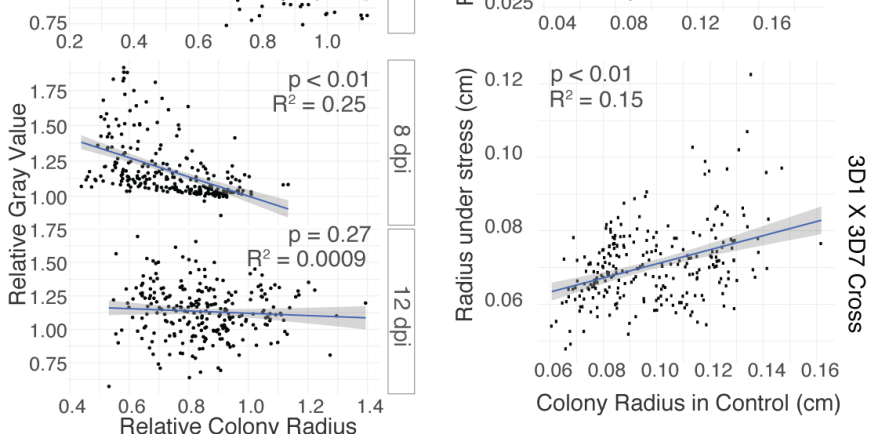

B

1 A5

1E4

3D7

3D1
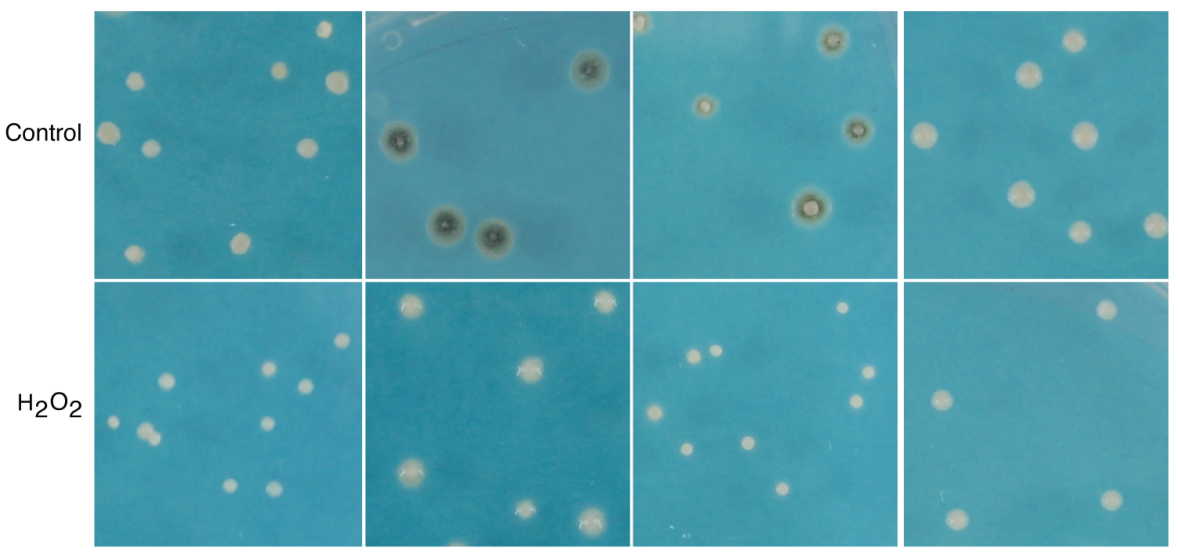

D

\section{Correlation}

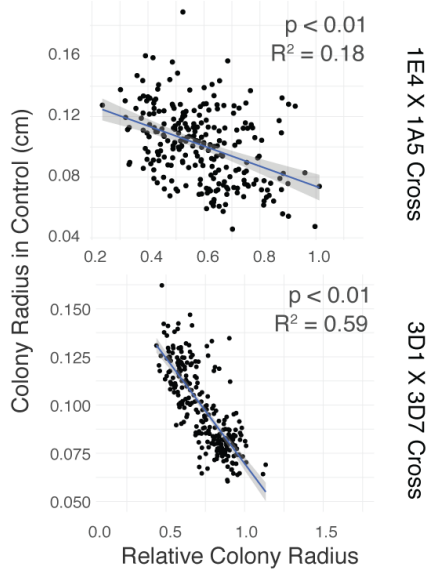


1E4 X 1A5 Cross

A

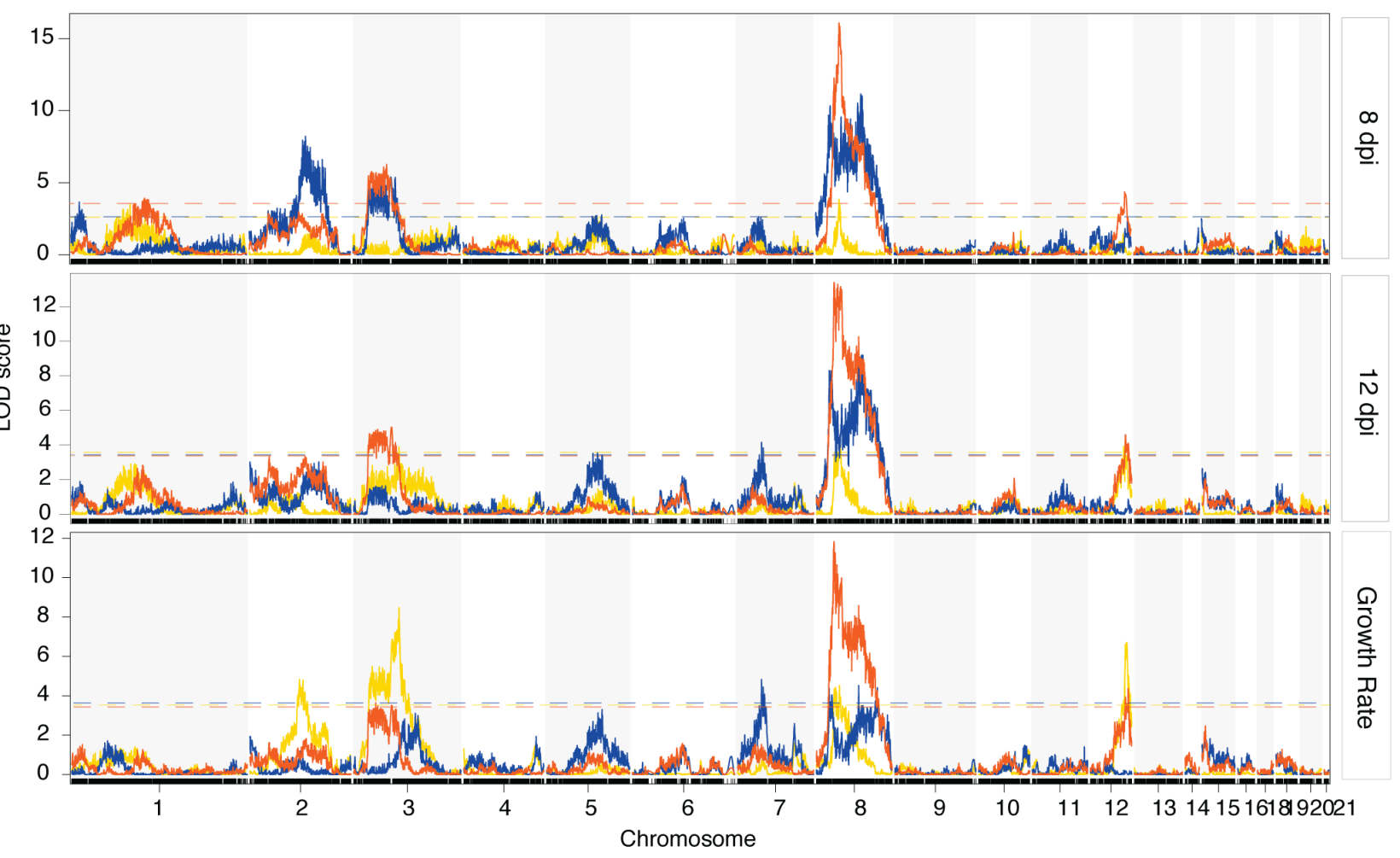

3D1 X 3D7 Cross

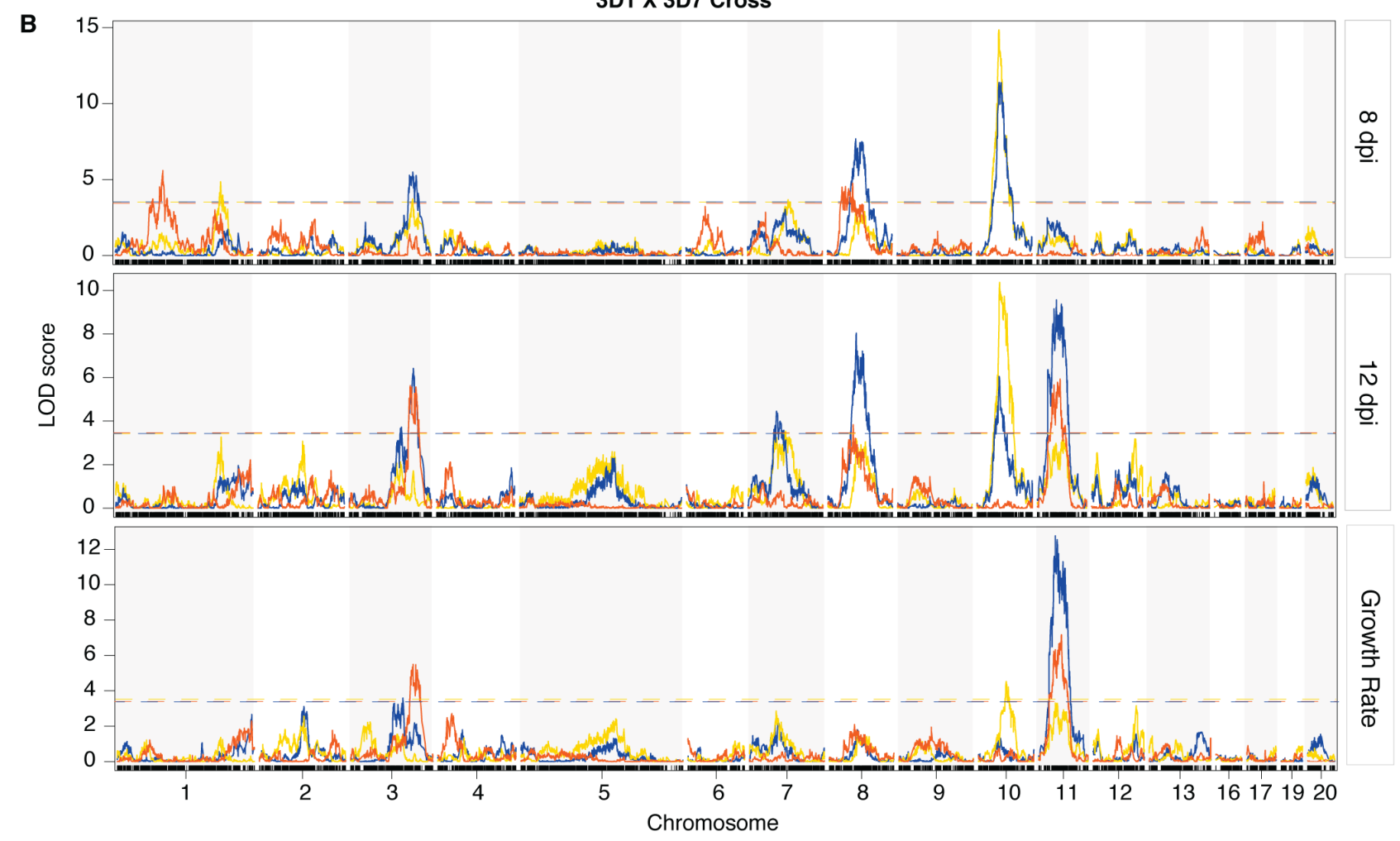


1E4 x 1 A5 Cross

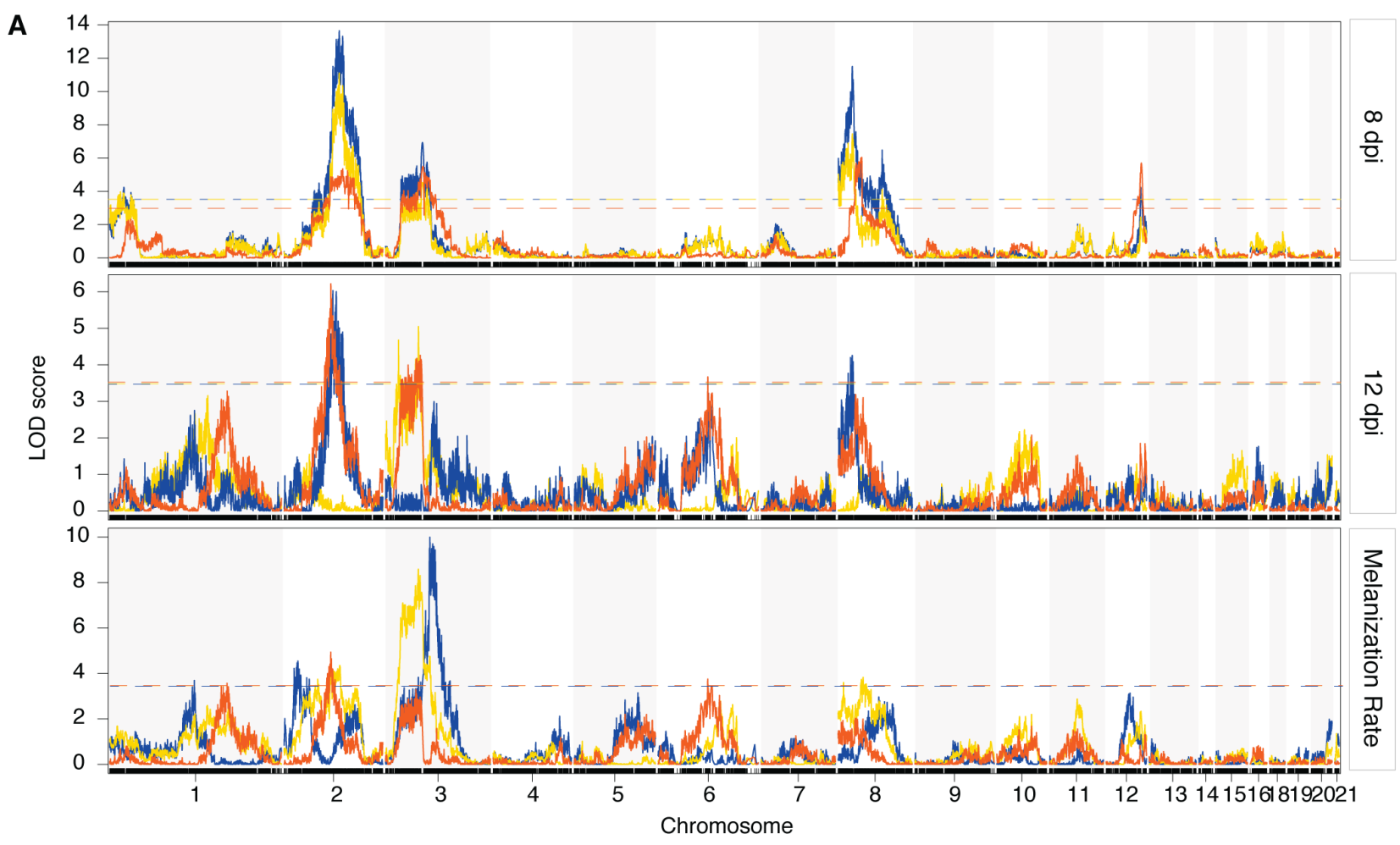

B

3D1 $\times$ 3D7 Cross

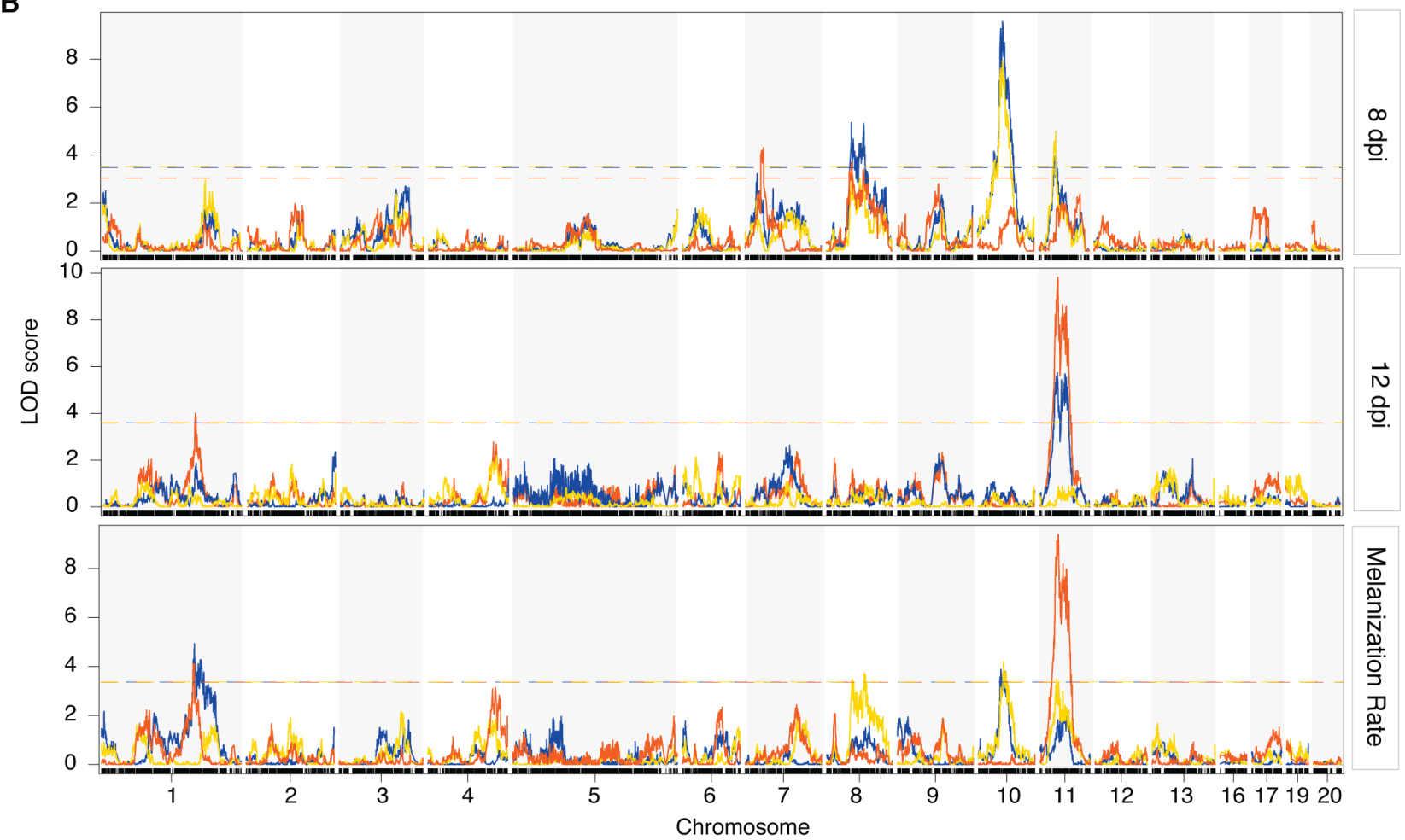


A

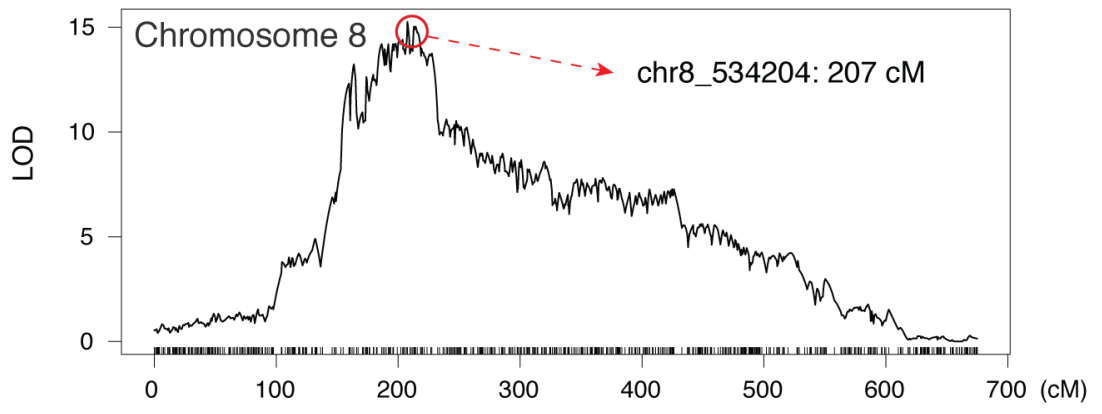

B

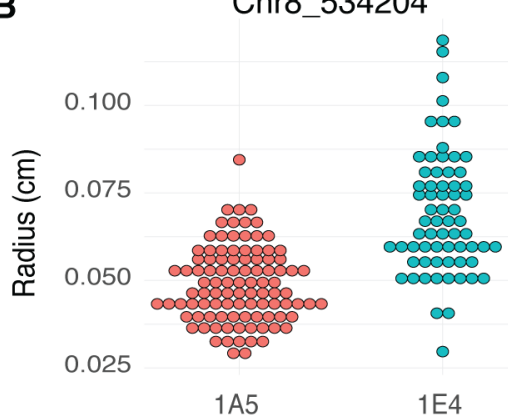

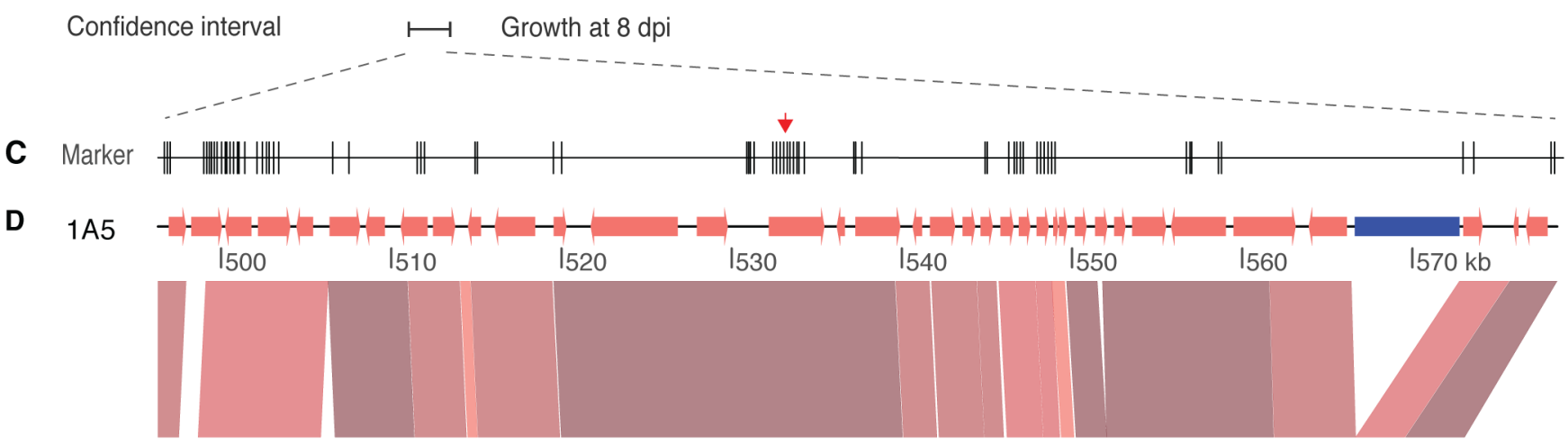

1E4

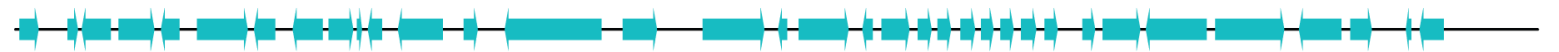

E

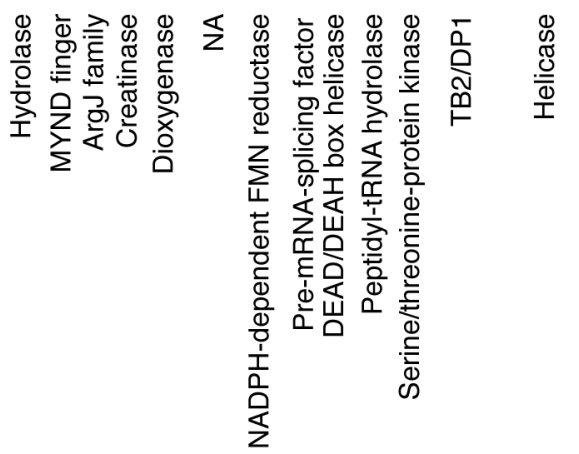


A

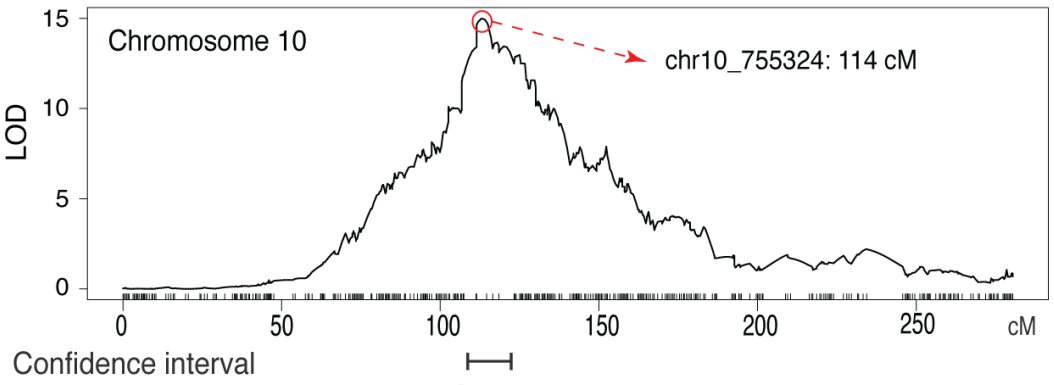

B

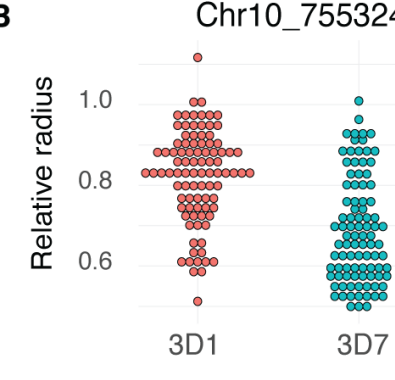

C Marker

D $3 \mathrm{D} 1$

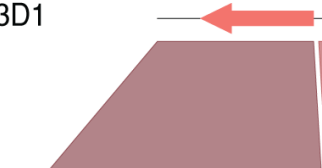

3D7
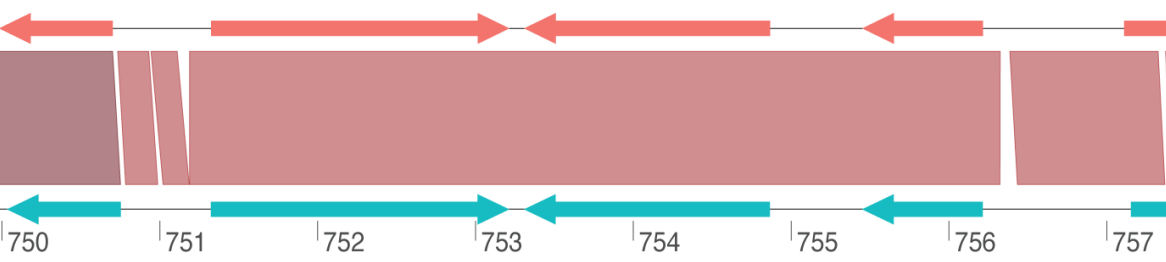

152

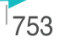

| 754

${ }^{I} 755$

I 756

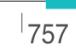

758

$1759 \mathrm{~kb}$

E Gene ID

3D7.99786

3D7.99787

3D7.99788

3D7.99789

3D7.99790

IPO323 ID

10_00216

10_00217

$10 \quad 00218$

10_00219

10_00220

Domain

NA

Ferric reductase

MFS

Acetyltransferase

NA

Polymorphisms

$\begin{array}{ll}\text { Protein } & 0 \\ \text { 5' UTR } & 7 \text { indels }+1 \\ \text { 3' UTR } & 2\end{array}$

(NOX)

$2(1 \%)$

$2(1 \%)$

$4(1 \%)$

3' UTR

7

77 indels +1

15

2

0

0

3D7.99788

7

6

3D7.g9787
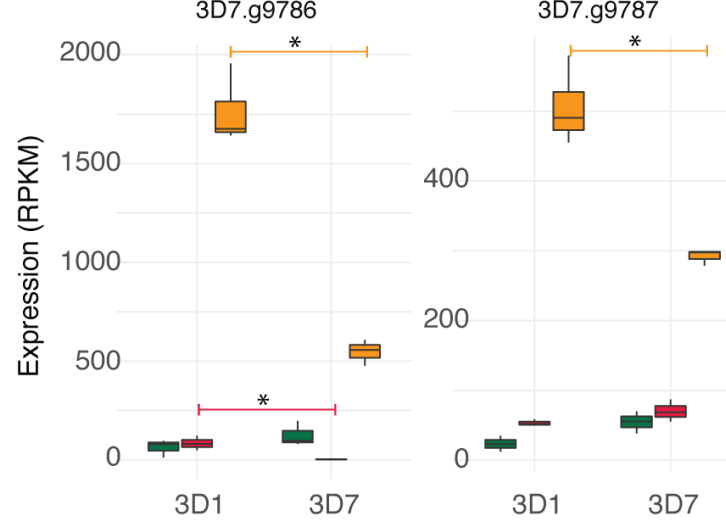

400

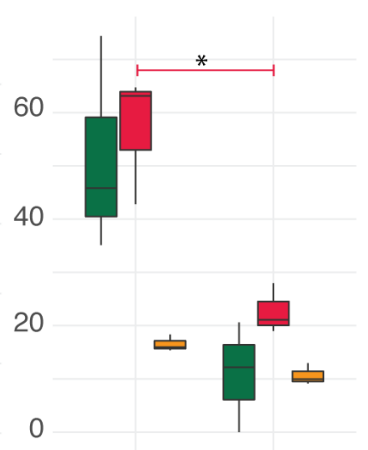

3D7.99789

3D7.99790

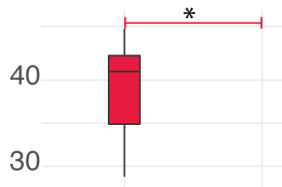

20

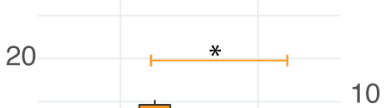

200
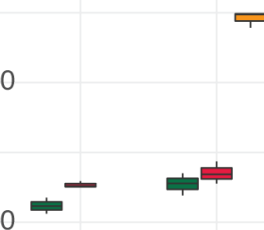

3D1 3D7

3D1

3D7

0

In planta 7dpi

Starvation

$\rightleftarrows$ YSB 